\title{
Study of 1-Deoxy-D-xylulose-5-phosphate Reductoisomerase: Synthesis and Evaluation of Fluorinated Substrate Analogues
}

\section{Supporting Information}

\author{
Alexander Wong, ${ }^{\ddagger}$ Jeffrey W. Munos, Vidusha Devasthali ${ }^{\S}$, Kenneth A. Johnson, \\ and Hung-wen Liu*
}

General. NMR chemical shifts ( $\delta$ in ppm) are given relative to those for TMS (for ${ }^{1} \mathrm{H}$ and ${ }^{13} \mathrm{C}$ ), with coupling constants in hertz $(\mathrm{Hz})$. The pET24(+) vector and the overexpression host strain Escherichia coli BL21(DE3) were purchased from Novagen Inc. (Madison, WI). Cloned DNA polymerase $P f u$ and GeneClean DNA purification kits were obtained from Stratagene (La Jolla, CA) and Bio 101 Inc. (La Jolla, CA), respectively. Primers used in PCR amplification were customarily prepared by Integrated DNA Technologies, Inc. (Coralville, IA) and used without further purification. Restriction endonucleases were purchased from Invitrogen (Carlsbad, CA). All electrophoretic reagents were obtained from Bio-Rad (Hercules, CA). Culture media were products of Difco (Detroit, MI), and the $\mathrm{Ni}$-NTA agarose resin was purchased from Qiagen (Valencia, CA). All chemicals were purchased from Sigma-Aldrich (St. Louis, MO), or Fisher Scientific (Pittsburgh, PA).

Cloning, Over-expression and Purification of DXR. DXR was amplified from the isolated E. coli genomic DNA by polymerase chain reaction (PCR) using the forward primer (DXRhis1): 5'-GCCGCGCATATGAAGCAACTCACCATTC-3', which contains an NdeI restriction site, and the reverse primer (DXRhis-2): 5'-AAACTCG-AGGCTTGCGAGACGATCAC-3', which contains an XhoI restriction site. The PCR-amplified DNA fragment was digested with NdeI and XhoI, and ligated into the NdeI/XhoI sites of the transcription vector, pET24(+), to give a 
recombinant plasmid. This plasmid was used to transform E. coli BL21(DE3). An overnight culture of the recombinant strain grown in Luria-Bertani (LB) medium supplemented with kanamycin $(50 \mu \mathrm{g} / \mathrm{mL})$ at $37{ }^{\circ} \mathrm{C}$ was used to inoculate a $1 \mathrm{~L}$ culture of the same medium and antibiotic. These cultures were incubated at $37{ }^{\circ} \mathrm{C}$ until the $\mathrm{OD}_{600}$ reached 0.45 , followed by induction with $1.0 \mathrm{mM}$ isopropyl $\beta$-D-thiogalactoside (IPTG) and $3.5 \mathrm{~h}$ of additional incubation at $37{ }^{\circ} \mathrm{C}$. The cells were harvested by centrifugation $(6000 \mathrm{~g}, 10 \mathrm{~min})$. Purification of this $\mathrm{C}-$ terminal $\mathrm{His}_{6}$-tagged protein by $\mathrm{Ni}$-NTA agarose resin was performed at $4{ }^{\circ} \mathrm{C}$ according to the procedures recommended by the manufacturer, except the elution buffer was $100 \mathrm{mM}$ imidazole. The concentrated purified protein was aliquotted, flash frozen in $30 \%$ glycerol, and stored at -80 ${ }^{\circ} \mathrm{C}$.

Active Site Titration of $\boldsymbol{D X R}$. The concentration of active DXR was determined via active site titration using NADPH as the titrant. A $2 \mathrm{~mL} 100 \mathrm{mM}$ Tris. $\mathrm{HCl}(\mathrm{pH}$ 7.6) solution containing $2 \mathrm{mM} \mathrm{MgCl} 2$ and $3.13 \mu \mathrm{M}$ DXR (based on Bradford assay) was titrated against a $400 \mu \mathrm{M}$ NADPH solution. The binding of NADPH to DXR was monitored by the increase in fluorescence of NADPH upon binding to the active site. The excitation and emission wavelengths were 340 and $458 \mathrm{~nm}$, respectively; and the excitation and emission slit widths were set at 1 and $5 \mathrm{~nm}$, respectively. To correct for the background fluorescence of free NADPH, a control titration without DXR was performed and subtracted from the titration with DXR. This data was then fit, using Grafit 5.0.1, to Equation 1 with $F_{o}, F_{\infty}, E_{o}$ and $K_{D}$ as parameters, where $F_{o}$ is starting fluorescence, $F_{\infty}$ is final fluorescence, $E_{o}$ is total DXR concentration, and $S_{o}$ is total NADPH concetration. ${ }^{\mathrm{S} 1}$

$$
F=F_{o}+\left(\frac{E_{o}+S_{o}+K_{D}-\sqrt{\left(E_{o}+S_{o}+K_{D}\right)^{2}-4 E_{o} S_{o}}}{2 E_{o}}\right)\left(F_{\infty}-F_{o}\right)
$$

${ }^{\text {S1 }}$ Anderson, K. S., Sikorski, J. A. and Johnson, K. A. Biochemistry 1988, 27, 1604-1610. 
This fit led a DXR concentration of $1.85 \pm 0.23 \mu \mathrm{M}$, which was then used to determine the stock DXR concentration. This fit also allowed us to deduce a $K_{\mathrm{D}}$ of $0.45 \pm 0.15 \mu \mathrm{M}$ for NADPH, which is very similar to its reported $K_{\mathrm{m}}$ of $0.5 \mu \mathrm{M} .^{14}$

DXR Assay and Inhibition Study. Enzyme assays were performed in triplicate according to the procedure reported in reference 14. The reaction mixture contained $200 \mu \mathrm{L}$ of degassed 100 $\mathrm{mM}$ Tris· $\mathrm{HCl}$ buffer ( $\mathrm{pH}$ 7.6), $1 \mathrm{mM} \mathrm{MgCl}, 1 \mathrm{mg} / \mathrm{mL}$ bovine serum albumin (BSA), $0.15 \mathrm{mM}$ NADPH, $23 \mathrm{nM}$ DXR, and varied concentrations of DXP (1). The $k_{c a t}$ and $K_{\mathrm{m}}$ for DXP were determined to be $21.3 \mathrm{~s}^{-1}$ and $61 \mu \mathrm{M}$, respectively, which are lower than the literature values of $107 \mathrm{~s}^{-1}$ and $115 \mu \mathrm{M}^{14}$ The low activity may be due to the presence of the C-terminal His ${ }_{6}$ tag. For inhibition studies, varied amounts of inhibitor $(5,6$, or $\mathbf{7})$ were added to the above reaction mixture minus the DXR, and the resulting solution was incubated at $37^{\circ} \mathrm{C}$ in a quartz cuvette for 15 min. The reaction was initiated by the addition of DXR and monitored by the consumption of NADPH at $340 \mathrm{~nm}$. The inhibitor concentration was determined by NMR by comparing the integration of the C-1 methyl signal of $\mathbf{6}$ (or 7 ) to that of a methanol internal standard of known concentration. The concentration of DXP (1) and $\mathbf{5}$ was determined as described in reference 14.

Figure 1

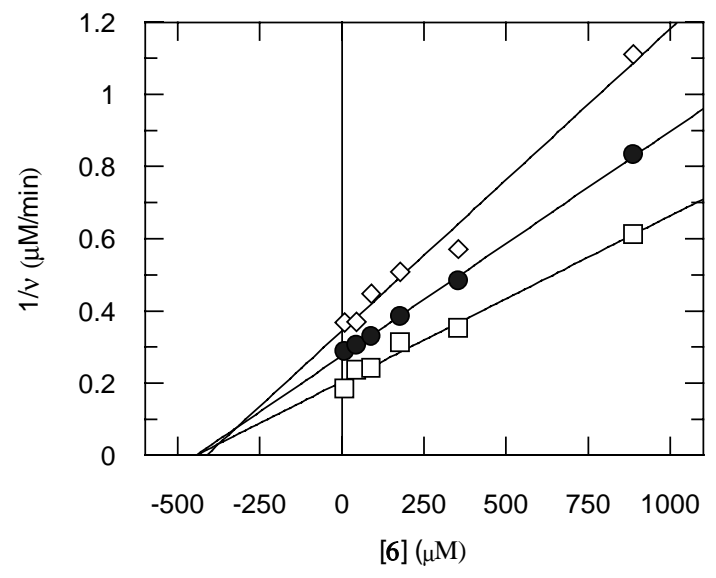

Figure 1. Dixon plot of the reciprocal of the reaction velocity observed $(v)$ as a function of the concentration of 6 ([I], varied from 0.05 to $5 \mathrm{mM}$ ) in the presence of $50 \mu \mathrm{M}(\Omega), 75 \mu \mathrm{M}(\bullet)$ and $100 \mu \mathrm{M}(\square) \operatorname{DXP}(\mathbf{1})$. 
Synthesis of 1-Deoxy-1-fluoro-D-xylulose-5-phosphate (1-Fluoro-DXP) (5). 1,2-OIsopropylidene-3-O-benzyl-5-deoxy-5-fluoro- $\beta$-D-arabinofuranose $(\mathbf{9})$. To a cooled $\left(4{ }^{\circ} \mathrm{C}\right)$ solution of 3-O-benzyl-1,2-O-isopropylidene- $\beta$-D-arabinofuranose $(\mathbf{8})^{22}(3.42 \mathrm{~g}, 12.2 \mathrm{mmol})$ in $100 \mathrm{~mL}$ of dry methylene chloride was added dry pyridine $(3.0 \mathrm{~mL}, 3 \mathrm{eq})$ followed by trifluoromethanesulfonic anhydride ( $3.1 \mathrm{~mL}, 1.5 \mathrm{eq})$. The solution was allowed to stir for $30 \mathrm{~min}$ then washed with $1 \mathrm{~N} \mathrm{HCl}$. The aqueous phase was re-extracted with $2 \times 50 \mathrm{~mL}$ methylene chloride and the organic layers were pooled, dried over magnesium sulfate and concentrated in vacuo. The reddish syrup was dissolved in $100 \mathrm{~mL}$ of THF and cooled to $4{ }^{\circ} \mathrm{C}$. To this solution was added $1 \mathrm{M}$ tetrabutylammonium fluoride in $\operatorname{THF}(1.15 \mathrm{~g}, 2.5 \mathrm{eq})$ and the resulting mixture was stirred at $4{ }^{\circ} \mathrm{C}$ overnight. The mixture was concentrated in vacuo and purified by silica gel chromatography (5:1 hexanes-ethyl acetate) to afford 9 as a syrup (1.36 g, 42\%). ${ }^{1} \mathrm{H}-\mathrm{NMR}(250$ $\left.\mathrm{MHz}, \mathrm{CDCl}_{3}\right) \delta 7.45-7.25(\mathrm{~m}, 5 \mathrm{H}, \mathrm{Ph}), 5.90\left(\mathrm{dd}, 1 \mathrm{H}, J_{1,2}=3.9 \mathrm{~Hz}, J_{1, \mathrm{~F}}=1.4 \mathrm{~Hz}, 1-\mathrm{H}\right) ; 4.66(\mathrm{~d}$, $\left.1 \mathrm{H}, J_{2,1}=3.9 \mathrm{~Hz}, 2-\mathrm{H}\right), 4.64(\mathrm{~d}, 1 \mathrm{H}, J=11.6 \mathrm{~Hz}, \mathrm{CH}-H-\mathrm{Ph}), 4.56(\mathrm{~d}, 1 \mathrm{H}, J=11.8 \mathrm{~Hz}, \mathrm{CH}-H-$ $\mathrm{Ph}), 4.50\left(\mathrm{dd}, 2 \mathrm{H}, J_{5,4}=5.2 \mathrm{~Hz}, J_{5, \mathrm{~F}}=47.6 \mathrm{~Hz}, 5-\mathrm{H}\right), 4.33-4.18(\mathrm{~m}, 1 \mathrm{H}, 4-\mathrm{H}), 4.04\left(\mathrm{~d}, 1 \mathrm{H}, J_{3,4}\right.$ $=3.1 \mathrm{~Hz}, 3-\mathrm{H}), 1.50\left(\mathrm{~s}, 3 \mathrm{H},-\mathrm{CH}_{3}\right), 1.34\left(\mathrm{~s}, 3 \mathrm{H},-\mathrm{CH}_{3}\right) ;{ }^{13} \mathrm{C}-\mathrm{NMR}\left(63 \mathrm{MHz}, \mathrm{CDCl}_{3}\right) \delta$ 137.0, 128.5, 128.4, 128.0, 127.7, 113.0, 105.7, $82.6(\mathrm{~d}, J=21.9 \mathrm{~Hz}), 82.1(\mathrm{~d}, J=3.9 \mathrm{~Hz}), 81.8(\mathrm{~d}, J=$ 169.7 Hz), 71.9, 27.1, 26.3; ${ }^{19} \mathrm{~F}-\mathrm{NMR}\left(282 \mathrm{MHz}, \mathrm{CDCl}_{3}\right) \delta 5.47\left(\mathrm{dq}, J_{\mathrm{F}, 5}=47.6 \mathrm{~Hz}, J_{\mathrm{F}, 4}=18.1\right.$ $\mathrm{Hz})$.

1-Deoxy-1-fluoro-3,4-di-O-benzyl-D-xylitol (11). Compound 9 (1.36 g, $5.1 \mathrm{mmol})$ was dissolved in $50 \mathrm{~mL}$ of a solution of $2.5 \%(\mathrm{v} / \mathrm{v})$ sulfuric acid:methanol and heated at reflux for 2 h. After cooled to room temperature, the solution was neutralized with solid sodium bicarbonate and concentrated in vacuo. Water $(50 \mathrm{~mL})$ was added to the residue and the mixture extracted with $3 \times 50 \mathrm{~mL}$ of ethyl acetate. The organic layers were pooled, dried over magnesium sulfate 
and concentrated in vacuo. The crude product was dissolved in $20 \mathrm{~mL}$ of $N, N$-dimethylformamide, cooled to $4{ }^{\circ} \mathrm{C}$, and treated with $60 \%$ sodium hydride (200 mg, 1 eq), followed by stirring for $5 \mathrm{~min}$. To this solution was added benzyl bromide $(0.6 \mathrm{~mL}, 1 \mathrm{eq})$ and the mixture was allowed to run at room temperature overnight. The reaction was quenched by the addition of $5 \mathrm{~mL}$ of $1 \mathrm{~N} \mathrm{HCl}$ with stirring for $15 \mathrm{~min}$. After concentration in vacuo, the residue was redissolved in water $(10 \mathrm{~mL})$ and the mixture extracted with $3 \times 10 \mathrm{~mL}$ methylene chloride. The organic layers were pooled, dried over magnesium sulfate, and concentrated. Purification by silica gel chromatography (5:1 hexanes-ethyl acetate) afforded methyl 2,3-O-dibenzyl-5-deoxy5-fluoro- $\beta$-D-arabinofuranoside (10) as a syrup (1.28 g, $80 \%$ over 2 steps).

Compound 10 (1.28 g, $4.14 \mathrm{mmol})$ was dissolved in $20 \mathrm{~mL}$ of $p$-dioxane. To this solution was added $6.4 \mathrm{~mL}$ of $3 \mathrm{~N} \mathrm{HCl}$. The reaction mixture was heated at reflux overnight then neutralized with solid sodium bicarbonate. The aqueous layer was extracted with ethyl acetate (3 $\times 50 \mathrm{~mL}$ ), and the pooled organic layers dried over magnesium sulfate and concentrated in vacuo. The hemiacetal product was obtained as a light-yellow syrup $(1.08 \mathrm{~g}, 88 \%)$ after silica gel flash chromatography (1:1 ethyl acetate-hexanes). This hemiacetal product was dissolved in $20 \mathrm{~mL}$ of methanol and cooled to $4{ }^{\circ} \mathrm{C}$. To this solution was added sodium borohydride $(0.275 \mathrm{~g}$, 2 eq). The reaction mixture was stirred at room temperature for $2 \mathrm{~h}$, then diluted with water $(50 \mathrm{~mL})$ and extracted with ethyl acetate $(3 \times 25 \mathrm{~mL})$. The organic layer was dried over magnesium sulfate and concentrated in vacuo. Purification by silica gel chromatography (1:1 ethyl acetate-hexanes) afforded $\mathbf{1 1}$ as a white solid $(1.01 \mathrm{~g}, 92 \%) .{ }^{1} \mathrm{H}-\mathrm{NMR}\left(300 \mathrm{MHz}, \mathrm{CDCl}_{3}\right) \delta$ 7.36-7.26 (m, $10 \mathrm{H}, \mathrm{Ph}), 4.62$ (s, $1 \mathrm{H}, \mathrm{CH}-H-\mathrm{Ph}), 4.61$ (s, $1 \mathrm{H}, \mathrm{CH}-H-\mathrm{Ph}), 4.59$ (s, $2 \mathrm{H}, \mathrm{CH}_{2}-\mathrm{Ph}$ ), $4.55\left(\mathrm{dd}, 2 \mathrm{H}, J_{1,2}=3.6 \mathrm{~Hz}, J_{1, \mathrm{~F}}=47.7 \mathrm{~Hz}, 1-\mathrm{H}\right), 4.00\left(\mathrm{ddt}, 1 \mathrm{H}, J_{2,1}=3.6 \mathrm{~Hz}, J_{2, \mathrm{~F}}=25.5 \mathrm{~Hz}, J_{2,3}\right.$ $=7.2 \mathrm{~Hz}, 2-\mathrm{H}), 3.88-3.68\left(\mathrm{~m}, 4 \mathrm{H}, 3-\mathrm{H}, 4-\mathrm{H}, 5-\mathrm{H}_{2}\right), 3.50(\mathrm{~s}, 2 \mathrm{H}, 2 \times-\mathrm{OH}) ;{ }^{13} \mathrm{C}-\mathrm{NMR}(75 \mathrm{MHz}$, $\left.\mathrm{CDCl}_{3}\right) \delta 137.4,137.3,128.6,128.5,128.3,128.2,128.1,84.2(\mathrm{~d}, J=169.3 \mathrm{~Hz}), 78.9,76.8(\mathrm{~d}, J$ 
$=5.5 \mathrm{~Hz}), 73.7,72.7,70.6(\mathrm{~d}, J=18.6 \mathrm{~Hz}), 60.9 ;{ }^{19} \mathrm{~F}-\mathrm{NMR}\left(282 \mathrm{MHz}, \mathrm{CDCl}_{3}\right) \delta-1.75\left(\mathrm{dq}, J_{\mathrm{F}, 1}=\right.$ $\left.47.7 \mathrm{~Hz}, J_{\mathrm{F}, 2}=25.5 \mathrm{~Hz}\right)$.

1-Deoxy-1-fluoro-3,4-di-O-benzyl-5-O-benzoyl-D-xylitol (12). To a solution of 11 (1.01 g, $3.39 \mathrm{mmol})$ in $15 \mathrm{~mL}$ of pyridine was added dropwise a solution of benzoyl chloride $(0.39 \mathrm{~mL}$, 1 eq.) in $10 \mathrm{~mL}$ of chloroform. After stirring for $16 \mathrm{~h}$ at room temperature the reaction mixture was diluted with $100 \mathrm{~mL}$ of $1 \mathrm{~N} \mathrm{HCl}$ and then extracted with ethyl acetate $(3 \times 50 \mathrm{~mL})$. The organic layers were pooled, dried over magnesium sulfate and concentrated in vacuo. The desired product 12 was isolated as a light-yellow syrup (1.17 g, 83\%) after silica gel flash chromatography (3:1 hexanes-ethyl acetate). ${ }^{1} \mathrm{H}-\mathrm{NMR}\left(250 \mathrm{MHz}, \mathrm{CDCl}_{3}\right) \delta$ 8.05-7.98 (m, $2 \mathrm{H}$, $\mathrm{Ph}), 7.65-7.25$ (m, $13 \mathrm{H}, \mathrm{Ph}), 4.76$ (d, $1 \mathrm{H}, J=11.7$, -CH-H-Ph), 4.66-4.56 (m, $5 \mathrm{H},-\mathrm{CH}_{2}-\mathrm{Ph}$, CH-H-Ph, 5-H $), 4.58\left(\mathrm{dd}, 2 \mathrm{H}, J_{1,2}=3.2 \mathrm{~Hz}, J_{1, \mathrm{~F}}=47.7 \mathrm{~Hz}, 1-\mathrm{H}\right), 4.14-3.96(\mathrm{~m}, 2 \mathrm{H}, 2-\mathrm{H}, 4-\mathrm{H})$, $3.76\left(\mathrm{dd}, 1 \mathrm{H}, J_{3,4}=3.4 \mathrm{~Hz}, J_{3,2}=8.0 \mathrm{~Hz}, 3-\mathrm{H}\right) ;{ }^{13} \mathrm{C}-\mathrm{NMR}\left(63 \mathrm{MHz}, \mathrm{CDCl}_{3}\right) \delta 166.2,137.3$, $137.2,133.6,133.1,130.1,129.7,129.6,128.5,128.4,128.3,128.2,128.1,128.0,82.8(\mathrm{~d}, J=$ $169.5 \mathrm{~Hz}), 76.3,75.9(\mathrm{~d}, J=5.8 \mathrm{~Hz}), 73.8,73.1,70.5(\mathrm{~d}, J=18.6 \mathrm{~Hz}), 63.5 ;{ }^{19} \mathrm{~F}-\mathrm{NMR}(282$ $\left.\mathrm{MHz}, \mathrm{CDCl}_{3}\right) \delta-2.90\left(\mathrm{dq}, J_{\mathrm{F}, 1}=47.7 \mathrm{~Hz}, J_{\mathrm{F}, 2}=26.0 \mathrm{~Hz}\right)$.

1-Deoxy-1-fluoro-3,4-di-O-benzyl-5-O-benzoyl-D-xylulose (13). $\quad$ To a cooled $\left(-60{ }^{\circ} \mathrm{C}\right)$ solution of $15 \mathrm{~mL}$ of oxalyl chloride $(0.44 \mathrm{~mL}, 2 \mathrm{eq})$ in anhydrous methylene chloride was added dimethyl sufoxide $(0.72 \mathrm{~mL}, 4 \mathrm{eq})$. After stirring for $15 \mathrm{~min}$, compound 12, dissolved in $2 \mathrm{~mL}$ of anhydrous methylene chloride, was added to the reaction mixture dropwise. The reaction was stirred for $5 \mathrm{~min}$ at $-60^{\circ} \mathrm{C}$, warmed to $-40^{\circ} \mathrm{C}$, and stirred for one more hour. Diisopropyl ethylamine $(2.6 \mathrm{~mL}, 6 \mathrm{eq})$ was then added and the reaction mixture was stirred for an additional $10 \mathrm{~min}$. The reaction was then washed with $50 \mathrm{~mL}$ of $1 \mathrm{~N} \mathrm{HCl}$. The organic layer was collected and the aqueous layer was extracted with methylene chloride $(2 \times 20 \mathrm{~mL})$. The organic phases were pooled, dried over magnesium sulfate, and concentrated in vacuo. Silica gel 
chromatography (2:1 ethyl acetate-hexanes) of the crude products afforded $\mathbf{1 3}$ as a light-yellow syrup $(0.62 \mathrm{~g}, 59 \%) .{ }^{1} \mathrm{H}-\mathrm{NMR}\left(300 \mathrm{MHz}, \mathrm{CDCl}_{3}\right) \delta$ 7.92-7.88 (m, $\left.2 \mathrm{H}, \mathrm{Ph}\right), 7.60-7.54(\mathrm{~m}, 1 \mathrm{H}$, Ph), 7.46-7.20 (m, $11 \mathrm{H}, \mathrm{Ph}), 5.15\left(\mathrm{dd}, 1 \mathrm{H} . J_{1,1}=17.3 \mathrm{~Hz}, J_{1, \mathrm{~F}}=47.1 \mathrm{~Hz}, 1-\mathrm{H}\right), 4.99(\mathrm{dd}, 1 \mathrm{H}$. $\left.J_{1^{\prime}, 1}=17.3 \mathrm{~Hz}, J_{1^{\prime}, \mathrm{F}}=47.1 \mathrm{~Hz}, 1^{\prime}-\mathrm{H}\right), 4.71(\mathrm{~d}, 1 \mathrm{H}, J=11.4,-\mathrm{CH}-H-\mathrm{Ph}), 4.70(\mathrm{~d}, 1 \mathrm{H}, J=11.4,-$ CH- $H-\mathrm{Ph}), 4.56-4.39\left(\mathrm{~m}, 4 \mathrm{H}, 2 \times-\mathrm{CH}-H-\mathrm{Ph}, 5-\mathrm{H}_{2}\right), 4.58\left(\mathrm{dd}, 2 \mathrm{H}, J_{1,2}=3.2 \mathrm{~Hz}, J_{1, \mathrm{~F}}=47.7 \mathrm{~Hz}\right.$, 1-H), $4.22\left(\mathrm{dd}, 1 \mathrm{H}, J_{3,4}=3.0 \mathrm{~Hz}, J_{3, \mathrm{~F}}=1.5 \mathrm{~Hz}, 3-\mathrm{H}\right), 4.15\left(\mathrm{ddd}, 1 \mathrm{H}, J_{4,3}=3.0 \mathrm{~Hz}, J_{4,5}=5.4 \mathrm{~Hz}\right.$, $\left.J_{4,5}=6.9 \mathrm{~Hz}, 4-\mathrm{H}\right) ;{ }^{13} \mathrm{C}-\mathrm{NMR}\left(63 \mathrm{MHz}, \mathrm{CDCl}_{3}\right) \delta 205.5(\mathrm{~d}, J=14.8 \mathrm{~Hz}), 165.8,136.8,136.0$, 133.2, 129.6, 129.4, 128.7, 128.5, 128.4, 128.3, 128.2, 128.1, 85.6 (d, $J=181.9 \mathrm{~Hz}), 82.2,77.2$, 74.4, 73.6, 61.8; ${ }^{19} \mathrm{~F}-\mathrm{NMR}\left(282 \mathrm{MHz}, \mathrm{CDCl}_{3}\right) \delta-2.63\left(\mathrm{t}, J_{\mathrm{F}, 1}=47.4 \mathrm{~Hz}\right)$.

1-Deoxy-1-fluoro-2-(1,3-dioxane)-3,4-di-O-benzyl-5-O-benzoyl-D-xylulose (14). To a solution of compound $\mathbf{1 3}(0.387 \mathrm{~g}, 0.925 \mathrm{mmol})$ in $6 \mathrm{~mL}$ of anhydrous benzene was added $2 \mathrm{~mL}$ of 1,3-propanediol and $p$-toluenesulfonic acid monohydrate (12 mg, $0.1 \mathrm{eq})$. The mixture was heated at reflux overnight under Dean-Stark conditions. Upon completion, the reaction was poured into $50 \mathrm{~mL}$ of saturated sodium bicarbonate and extracted with ethyl acetate $(3 \times 50 \mathrm{~mL})$. The combined organic phases were dried over magnesium sulfate and concentrated in vacuo. The desired product $\mathbf{1 4}$ was isolated after purification by silica gel chromatography (3:1 hexanesethyl acetate) as a syrup $(0.27 \mathrm{mg}, 71 \%) .{ }^{1} \mathrm{H}-\mathrm{NMR}\left(300 \mathrm{MHz}, \mathrm{CDCl}_{3}\right) \delta$ 8.02-7.98 (m, $\left.2 \mathrm{H}, \mathrm{Ph}\right)$, 7.58-7.50 (m, $1 \mathrm{H}, \mathrm{Ph}), 7.46-7.20(\mathrm{~m}, 11 \mathrm{H}, \mathrm{Ph}), 4.98\left(\mathrm{dd}, 1 \mathrm{H} . J_{1,1}{ }^{\prime}=10.1 \mathrm{~Hz}, J_{1, \mathrm{~F}}=47.5 \mathrm{~Hz}, 1-\right.$ H), $4.86(\mathrm{~d}, 1 \mathrm{H}, J=11.1$, -CH- $H-\mathrm{Ph}), 4.78(\mathrm{~d}, 1 \mathrm{H}, J=11.7$, -CH- $H-\mathrm{Ph}), 4.74\left(\mathrm{dd}, 1 \mathrm{H} . J_{1^{\prime}, 1}=\right.$ $\left.10.1 \mathrm{~Hz}, J_{1^{\prime}, \mathrm{F}}=47.5 \mathrm{~Hz}, 1^{\prime}-\mathrm{H}\right), 4.73(\mathrm{~d}, 1 \mathrm{H}, J=11.1,-\mathrm{CH}-H-\mathrm{Ph}), 4.71(\mathrm{~d}, 1 \mathrm{H}, J=11.7$, -CH- $H-$ $\mathrm{Ph}), 4.61\left(\mathrm{dd}, 1 \mathrm{H}, J_{5,4}=4.0 \mathrm{~Hz}, J_{5,5}=11.6 \mathrm{~Hz}, 5-\mathrm{H}\right), 4.46\left(\mathrm{dd}, 1 \mathrm{H}, J_{5^{\prime}, 4}=7.0 \mathrm{~Hz}, J_{5^{\prime}, 5}=11.6\right.$ $\mathrm{Hz}, 5 '-\mathrm{H}), 4.25-3.88\left(\mathrm{~m}, 5 \mathrm{H}, \mathrm{H}-4,2 \times-\mathrm{CH}_{2}-\right), 3.74\left(\mathrm{dd}, 1 \mathrm{H}, J_{3,4}=2.4 \mathrm{~Hz}, J_{3, \mathrm{~F}}=6.0 \mathrm{~Hz}, 3-\mathrm{H}\right)$, 2.14-1.94 (m, $1 \mathrm{H},-\mathrm{CH}-H-), 1.58-1.48(\mathrm{~m}, 1 \mathrm{H},-\mathrm{CH}-\mathrm{H}-) ;{ }^{13} \mathrm{C}-\mathrm{NMR}\left(63 \mathrm{MHz}, \mathrm{CDCl}_{3}\right)$ $\delta 166.4,138.4,137.9,132.8,130.2,129.6,128.4,128.3,128.2,128.1,127.7,127.5,98.2(\mathrm{~d}, J=$ 
$17.7 \mathrm{~Hz}), 79.3,78.7(\mathrm{~d}, J=176.2 \mathrm{~Hz}), 76.5,75.3,73.8,65.7 ; 61.1,60.3,24.6 ;{ }^{19} \mathrm{~F}-\mathrm{NMR}(282$ $\left.\mathrm{MHz}, \mathrm{CDCl}_{3}\right) \delta-2.78\left(\mathrm{t}, J_{\mathrm{F}, 1}=47.4 \mathrm{~Hz}\right)$.

1-Deoxy-1-fluoro-2-(1,3-dioxane)-3,4-di-O-benzyl-D-xylulose (15). To a solution of 14 $(0.27 \mathrm{mg}, 0.60 \mathrm{mmol})$ in $6 \mathrm{~mL}$ of HPLC grade methanol was added $0.052 \mathrm{~mL}$ ( 0.25 eq.) of $2.8 \mathrm{M}$ sodium methoxide/methanol. The reaction mixture was stirred at room temperature for $4 \mathrm{~h}$, then neutralized by successive additions of concentrated sulfuric acid and triethylamine. The reaction mixture was concentrated in vacuo and purified by silica gel chromatography (3:1 hexanes-ethyl acetate) to yield 15 as a gum $(0.166 \mathrm{~g}, 77 \%) .{ }^{1} \mathrm{H}-\mathrm{NMR}\left(300 \mathrm{MHz}, \mathrm{CDCl}_{3}\right) \delta$ 7.37-7.26 (m, $10 \mathrm{H}$, Ph), $4.98\left(\mathrm{dd}, 1\right.$ H. $\left.J_{1,1}=10.2 \mathrm{~Hz}, J_{1, \mathrm{~F}}=47.4 \mathrm{~Hz}, 1-\mathrm{H}\right), 4.86(\mathrm{~d}, 1 \mathrm{H}, J=10.8$, -CH- $H-\mathrm{Ph}), 4.80$ (d, $1 \mathrm{H}, J=11.4,-\mathrm{CH}-H-\mathrm{Ph}), 4.70\left(\mathrm{dd}, 1 \mathrm{H} . J_{1^{\prime}, 1}=10.2 \mathrm{~Hz}, J_{1^{\prime}, \mathrm{F}}=47.4 \mathrm{~Hz}, 1^{\prime}-\mathrm{H}\right), 4.67$ (d, $1 \mathrm{H}, J$ $=10.8,-\mathrm{CH}-H-\mathrm{Ph}), 4.64(\mathrm{~d}, 1 \mathrm{H}, J=11.4,-\mathrm{CH}-H-\mathrm{Ph}), 4.15-3.64(\mathrm{~m}, 8 \mathrm{H}, 3-\mathrm{H}, 4-\mathrm{H}, 5-\mathrm{H}, 5$ '-H, 2 $\left.\times-\mathrm{CH}_{2}-\right), 2.23\left(\mathrm{dd}, 1 \mathrm{H}, J_{\mathrm{H}, 5}=5.1 \mathrm{~Hz}, J_{\mathrm{H}, 5^{\prime}}=8.7 \mathrm{~Hz},-\mathrm{OH}\right), 2.11-1.95(\mathrm{~m}, 1 \mathrm{H},-\mathrm{CH}-H-), 1.57-$ $1.48(\mathrm{~m}, 1 \mathrm{H},-\mathrm{CH}-H-) ;{ }^{13} \mathrm{C}-\mathrm{NMR}\left(63 \mathrm{MHz}, \mathrm{CDCl}_{3}\right) \delta$ 138.6, 138.0, 128.4, 128.3, 128.2, 128.0, 127.7, 127.6, $98.3(\mathrm{~d}, J=18.6 \mathrm{~Hz}), 79.4,79.3,77.7(\mathrm{~d}, J=176.6 \mathrm{~Hz}), 75.4,73.6,63.5 ;$; 61.0, 60.3, 24.6; ${ }^{19} \mathrm{~F}-\mathrm{NMR}\left(282 \mathrm{MHz}, \mathrm{CDCl}_{3}\right) \delta-2.98\left(\mathrm{t}, J_{\mathrm{F}, 1}=47.4 \mathrm{~Hz}\right)$.

Dimethyl 1-Deoxy-1-fluoro-2-(1,3-dioxane)-3,4-di-O-benzyl-D-xylulose-5-phosphate (16). To a solution of alcohol $15(0.071 \mathrm{~g}, 0.20 \mathrm{mmol})$ in $1 \mathrm{~mL}$ of anhydrous methylene chloride was added 2,6-lutidine $(0.032 \mathrm{~mL}, 1.4 \mathrm{eq})$ and trimethyl phosphite $(0.028 \mathrm{~mL}, 1.2 \mathrm{eq})$. To this was added tellurium tetrachloride $(0.067 \mathrm{mg}, 1.2 \mathrm{eq})$. The reaction mixture was stirred at room temperature for $1.5 \mathrm{~h}$, then filtered through Celite 545 and concentrated in vacuo. Silica gel chromatography (1:1 ethyl acetate-hexanes) of the crude products yielded $\mathbf{1 6}$ as a clear syrup (0.044 g, 47\%). ${ }^{1} \mathrm{H}-\mathrm{NMR}\left(300 \mathrm{MHz}, \mathrm{CDCl}_{3}\right) \delta$ 7.38-7.25 (m, $\left.10 \mathrm{H}, \mathrm{Ph}\right), 4.93\left(\mathrm{dd}, 1 \mathrm{H} . J_{1,1}{ }^{\prime}=\right.$ $\left.10.2 \mathrm{~Hz}, J_{1, \mathrm{~F}}=47.4 \mathrm{~Hz}, 1-\mathrm{H}\right), 4.78(\mathrm{~d}, 1 \mathrm{H}, J=10.8$, - $\mathrm{CH}-\mathrm{H}-\mathrm{Ph}), 4.75(\mathrm{~d}, 1 \mathrm{H}, J=11.1,-\mathrm{CH}-H-$ Ph), $4.69\left(\mathrm{dd}, 1 \mathrm{H} . J_{1^{\prime}, 1}=10.2 \mathrm{~Hz}, J_{1^{\prime}, \mathrm{F}}=47.4 \mathrm{~Hz}, 1^{\prime}-\mathrm{H}\right), 4.69(\mathrm{~d}, 1 \mathrm{H}, J=10.8$, -CH- $H-\mathrm{Ph}), 4.67$ 
$(\mathrm{d}, 1 \mathrm{H}, J=11.1,-\mathrm{CH}-H-\mathrm{Ph}), 4.35\left(\mathrm{ddd}, 1 \mathrm{H}, J_{5,4}=3.6 \mathrm{~Hz}, J_{5, \mathrm{P}}=6.9 \mathrm{~Hz}, J_{5,5^{\prime}}=10.2 \mathrm{~Hz}, 5-\mathrm{H}\right)$, 4.18-3.90 (m, $6 \mathrm{H}, 4-\mathrm{H}, 5$ '- $\left.\mathrm{H}, 2 \times-\mathrm{CH}_{2}-\right), 3.74\left(\mathrm{~d}, 3 \mathrm{H}, J=1 \mathrm{~Hz},-\mathrm{OCH}_{3}\right), 3.73\left(\mathrm{dd}, 1 \mathrm{H}, J_{3,4}=\right.$ $\left.2.1 \mathrm{~Hz}, J_{3, \mathrm{~F}}=5.7 \mathrm{~Hz}\right), 3.71\left(\mathrm{~d}, 3 \mathrm{H}, J=1 \mathrm{~Hz},-\mathrm{OCH}_{3}\right), 2.07-1.90(\mathrm{~m}, 1 \mathrm{H},-\mathrm{CH}-H-), 1.60-1.49(\mathrm{~m}$, $1 \mathrm{H},-\mathrm{CH}-\mathrm{H}-$ ); ${ }^{13} \mathrm{C}-\mathrm{NMR}\left(63 \mathrm{MHz}, \mathrm{CDCl}_{3}\right) \delta 138.3,137.8,128.3,128.2,128.1,127.9,127.6$, 127.4, $98.0(\mathrm{~d}, J=18.0 \mathrm{~Hz}), 78.5,78.5(\mathrm{~d}, J=176.2 \mathrm{~Hz}), 77.2(\mathrm{~d}, J=7.2 \mathrm{~Hz}), 75.3,73.9,68.2$ $(\mathrm{d}, J=5.7 \mathrm{~Hz}), 60.9,60.2,54.1,54.024 .6 ;{ }^{19} \mathrm{~F}-\mathrm{NMR}\left(282 \mathrm{MHz}, \mathrm{CDCl}_{3}\right) \delta-3.05\left(\mathrm{t}, J_{\mathrm{F}, 1}=48.0\right.$ $\mathrm{Hz}) ;{ }^{31} \mathrm{P}-\mathrm{NMR}\left(121 \mathrm{MHz}, \mathrm{CDCl}_{3}\right) \delta 2.48$.

1-Deoxy-1-fluoro-D-xylulose-5-phosphate (5). To a solution of $\mathbf{1 6}(0.040 \mathrm{~g}, 0.091 \mathrm{mmol})$ in $0.65 \mathrm{~mL}$ of deuterated chloroform was added trimethylsilyl bromide ( $26 \mu \mathrm{L}, 2.2 \mathrm{eq}$.$) , and the$ solution was stirred for $1.5 \mathrm{~h}$. The reaction mixture was then concentrated in vacuo and redissolved in $0.1 \mathrm{~mL}$ of water and $0.9 \mathrm{~mL}$ of methanol. To this solution was added $5 \mathrm{mg}$ of $10 \%$ palladium on carbon and the reaction was stirred under hydrogen gas for $17 \mathrm{~h}$. The reaction was then filtered through Celite and concentrated in vacuo. The residue was dissolved in $500 \mu \mathrm{L}$ of $1 \mathrm{~N} \mathrm{HCl}$ in $\mathrm{D}_{2} \mathrm{O}$ and shaken at $37{ }^{\circ} \mathrm{C}$ for $12 \mathrm{~h}$. Hydrolysis of the ketal protecting group was followed by ${ }^{1} \mathrm{H}-\mathrm{NMR}$. Prolonged reaction time led to decomposition of the desired product. Thus, after $12 \mathrm{~h}$, the solution was neutralized with solid sodium bicarbonate and lyophilized. The product was purified by cellulose chromatography (Whatman CF-11) (9:1 tetrahydrofuran-0.1\% aqueous trifluoroacetic acid); however, the low stability of $\mathbf{5}$ caused it to partially decompose in the column. Thus, the partially purified product (approximately 80\%) was used without further purification in the enzymatic studies. ${ }^{1} \mathrm{H}-\mathrm{NMR}\left(500 \mathrm{MHz}, \mathrm{D}_{2} \mathrm{O}\right) \delta 5.36\left(\mathrm{dd}, 1 \mathrm{H}, J_{1,1}=17.5 \mathrm{~Hz}\right.$, $\left.J_{1, \mathrm{~F}}=46.5 \mathrm{~Hz}, 1-\mathrm{H}\right), 5.26\left(\mathrm{dd}, 1 \mathrm{H}, J_{1^{\prime}, 1}=17.5 \mathrm{~Hz}, J_{1^{\prime}, \mathrm{F}}=46.5 \mathrm{~Hz}, 1^{\prime}-\mathrm{H}\right), 4.50\left(\mathrm{~d}, J_{3,4}=2.0 \mathrm{~Hz}, 3-\right.$ $\mathrm{H}), 4.17\left(\mathrm{dt}, 1 \mathrm{H}, J_{4,3}=2.0 \mathrm{~Hz}, J_{4,5}=J_{4,5}=6.5 \mathrm{~Hz}, 4-\mathrm{H}\right), 3.85\left(\mathrm{t}, 1 \mathrm{H}, J_{5,4}=J_{5,5}=6.5 \mathrm{~Hz}, 5-\mathrm{H}\right)$, $3.83\left(\mathrm{t}, 1 \mathrm{H}, J_{5^{\prime}, 4}=J_{5^{\prime}, 5}=6.5 \mathrm{~Hz}, 5^{\prime}-\mathrm{H}\right) ;{ }^{13} \mathrm{C}-\mathrm{NMR}\left(126 \mathrm{MHz}, \mathrm{D}_{2} \mathrm{O}\right) \delta 85.4\left(\mathrm{~d}, J_{1, \mathrm{~F}}=163 \mathrm{~Hz}, \mathrm{C}-\right.$ 
1), $75.1(\mathrm{C}-3), 70.6(\mathrm{C}-4), 64.8(\mathrm{C}-5) ;{ }^{19} \mathrm{~F}-\mathrm{NMR}\left(470 \mathrm{MHz}, \mathrm{D}_{2} \mathrm{O}\right) \delta-234.66(\mathrm{t}, J=46.5 \mathrm{~Hz}) ;{ }^{31} \mathrm{P}-$ NMR (121 MHz, $\left.\mathrm{D}_{2} \mathrm{O}\right) \delta$ 1.53. HRMS (CI) cald for $\mathrm{C}_{5} \mathrm{H}_{9} \mathrm{FO}_{7} \mathrm{P} 231.0070$; found 231.0073.

Synthesis of 3-Deoxy-3-fluoro-D-xylulose-5-phosphate (3-Fluoro-DXP) (6). Methyl 3Deoxy-3-fluoro-5-O-benzoyl- $\alpha$-D-arabinofuranoside (18). To a solution of $\mathbf{1 7}^{24,25}(0.848 \mathrm{~g}$, $5.1 \mathrm{mmol})$ in pyridine $(16 \mathrm{~mL})$ was added benzoyl chloride $(0.71 \mathrm{~mL}, 1.2 \mathrm{eq}$.). The mixture was stirred at room temperature overnight. Methanol $(1 \mathrm{~mL})$ was added and the mixture stirred for 15 min, then concentrated in vacuo. The resulting residue was purified by silica gel chromatography (2:1 hexanes-ethyl acetate) to give 18 as a clear syrup $(1.07 \mathrm{~g}, 78 \%) .{ }^{1} \mathrm{H}-\mathrm{NMR}$ (250 MHz, $\left.\mathrm{CDCl}_{3}\right) \delta$ 8.10-8.00 (m, 2 H, Ph), 7.62-7.39 (m, 3 H, Ph), 4.96 (s, 1 H, H-1), 4.90 (dd, $\left.J_{3,4}=2.5 \mathrm{~Hz}, J_{3, \mathrm{~F}}=52.9 \mathrm{~Hz}, 3-\mathrm{H}\right), 4.62-4.46\left(\mathrm{~m}, 3 \mathrm{H},-\mathrm{CH}_{2}-\mathrm{OBz}, 4-\mathrm{H}\right), 4.36\left(\mathrm{~d}, 1 \mathrm{H}, J_{2, \mathrm{~F}}=15.0\right.$ $\mathrm{Hz}, 2-\mathrm{H}), 3.44$ (s, $\left.3 \mathrm{H},-\mathrm{OCH}_{3}\right) ;{ }^{13} \mathrm{C}-\mathrm{NMR}\left(63 \mathrm{MHz}, \mathrm{CDCl}_{3}\right) \delta$ 166.3, 133.3, 129.7, 129.5, 128.5, $109.2(\mathrm{~d}, J=27.4 \mathrm{~Hz}), 97.3(\mathrm{~d}, J=186.4 \mathrm{~Hz}), 80.5(\mathrm{~d}, J=27.7 \mathrm{~Hz}), 79.1(\mathrm{~d}, J=24.8 \mathrm{~Hz}), 63.6$ $(\mathrm{d}, J=6.5 \mathrm{~Hz}), 55.1(\mathrm{~d}, J=3.9 \mathrm{~Hz}) ;{ }^{19} \mathrm{~F}-\mathrm{NMR}\left(282 \mathrm{MHz}, \mathrm{CDCl}_{3}\right) \delta-187.8\left(\mathrm{ddd}, J_{\mathrm{F}, 4}=24.0 \mathrm{~Hz}\right.$ $\left.J_{\mathrm{F}, 3}=52.9 \mathrm{~Hz}, J_{\mathrm{F}, 2}=15.0 \mathrm{~Hz}\right)$. HRMS $(\mathrm{CI})$ cald for $\mathrm{C}_{13} \mathrm{H}_{16} \mathrm{FO}_{5} 271.0982$; found 271.0972 .

Methyl 2-O-Benzyl-3-deoxy-3-fluoro-5-O-benzoyl- $\alpha$-D-arabinofuranoside (19). To a solution of $18(1.01 \mathrm{~g}, 3.74 \mathrm{mmol})$ in $39 \mathrm{~mL}$ of $2: 1$ cyclohexane-methylene chloride was added benzyl 2,2,2-trichloroacetimidate (1.4 mL, 2 eq.) followed by 8 drops of trifluoro-methanesulfonic acid. The mixture was stirred at room temperature overnight, then filtered through Celite 545 to remove the trichloroacetamide byproduct and concentrated in vacuo. The residue was redissolved in $50 \mathrm{~mL}$ methylene chloride and washed with $50 \mathrm{~mL}$ of saturated sodium bicarbonate. The aqueous layer was re-extracted with methylene chloride $(2 \times 50 \mathrm{~mL})$. The organic layers were pooled, washed with water, then dried over magnesium sulfate and concentrated in vacuo. The desired product 19 was isolated as a light-yellow syrup $(0.872 \mathrm{~g}, 65 \%)$ after silica gel 
chromatography (5:1 hexanes-ethyl acetate). ${ }^{1} \mathrm{H}-\mathrm{NMR}\left(250 \mathrm{MHz}, \mathrm{CDCl}_{3}\right) \delta 8.10-8.00(\mathrm{~m}, 2 \mathrm{H}$, $\mathrm{Ph}), 7.56-7.24(\mathrm{~m}, 8 \mathrm{H}, \mathrm{Ph}), 5.01(\mathrm{~s}, 1 \mathrm{H}, 1-\mathrm{H}), 5.00\left(\mathrm{ddd}, J_{3,2}=1.7 \mathrm{~Hz}, J_{3,4}=3.9 \mathrm{~Hz}, J_{3, \mathrm{~F}}=52.9\right.$ Hz, 3-H), 4.64 (d, $1 \mathrm{H}, J=11.7 \mathrm{~Hz},-\mathrm{CH}-H-\mathrm{PH}), 4.59$ (d, $1 \mathrm{H}, J=11.7 \mathrm{~Hz},-\mathrm{CH}-H-\mathrm{PH}), 4.58-$ $4.42\left(\mathrm{~m}, 3 \mathrm{H},-\mathrm{CH}_{2}-\mathrm{OBz}, 4-\mathrm{H}\right), 4.16\left(\mathrm{dd}, 1 \mathrm{H}, J_{2,3}=1.7 \mathrm{~Hz}, J_{2, \mathrm{~F}}=17.0 \mathrm{~Hz}, 2-\mathrm{H}\right), 3.42(\mathrm{~s}, 3 \mathrm{H},-$ $\left.\mathrm{OCH}_{3}\right) ;{ }^{13} \mathrm{C}-\mathrm{NMR}\left(63 \mathrm{MHz}, \mathrm{CDCl}_{3}\right) \delta 166.1,136.8,133.1,129.7,129.5,128.9,128.4,128.3$, 128.2, 128.0, 127.8, 127.6, $107.0(\mathrm{~d}, J=5.5 \mathrm{~Hz}), 95.9(\mathrm{~d}, J=186.3 \mathrm{~Hz}), 86.8(\mathrm{~d}, J=24.2 \mathrm{~Hz})$, $79.6(\mathrm{~d}, J=27.7 \mathrm{~Hz}), 72.1,63.2(\mathrm{~d}, J=5.1 \mathrm{~Hz}), 55.0,45.2 ;{ }^{19} \mathrm{~F}-\mathrm{NMR}\left(282 \mathrm{MHz}, \mathrm{CDCl}_{3}\right) \delta-$ $187.8\left(\mathrm{ddd}, J_{\mathrm{F}, 4}=22.0 \mathrm{~Hz}, J_{\mathrm{F}, 3}=52.9 \mathrm{~Hz}, J_{\mathrm{F}, 2}=17.0 \mathrm{~Hz}\right.$ ). HRMS $(\mathrm{CI})$ cald for $\mathrm{C}_{20} \mathrm{H}_{22} \mathrm{FO}_{5}$ 361.1451; found 361.1442.

Methyl 2-O-Benzyl-3-deoxy-3-fluoro- $\alpha$-D-arabinofuranoside (20). Compound 19 (0.850 g, $2.36 \mathrm{mmol}$ ) was dissolved in $23 \mathrm{~mL}$ of HPLC grade methanol. To this stirred solution was added 2.8 M sodium methoxide/methanol (210 $\mu \mathrm{L}, 0.25$ eq. $)$. After stirring at room temperature for $3 \mathrm{~h}$, the mixture was neutralized by successive additions of concentrated sulfuric acid and triethylamine. The resulting suspension was concentrated in vacuo and the crude product purified by silica gel chromatography (2:1 hexanes-ethyl acetate) to yield $\mathbf{2 0}$ as a syrup $(0.4 \mathrm{~g}$, 66\%). ${ }^{1} \mathrm{H}-\mathrm{NMR}\left(300 \mathrm{MHz}, \mathrm{CDCl}_{3}\right) \delta 7.40-7.24(\mathrm{~m}, 5 \mathrm{H}, \mathrm{Ph}), 5.00\left(\mathrm{ddd}, J_{3,2}=2.1 \mathrm{~Hz}, J_{3,4}=4.5\right.$ $\left.\mathrm{Hz}, J_{3, \mathrm{~F}}=53.9 \mathrm{~Hz}, 3-\mathrm{H}\right), 4.96(\mathrm{~s}, 1 \mathrm{H}, 1-\mathrm{H}), 4.66(\mathrm{~d}, 1 \mathrm{H}, J=11.7 \mathrm{~Hz},-\mathrm{CH}-H-\mathrm{PH}), 4.56(\mathrm{~d}, 1 \mathrm{H}$, $J=11.7 \mathrm{~Hz},-\mathrm{CH}-H-\mathrm{PH}), 4.30\left(\mathrm{ddd}, J_{4,5}=3.0 \mathrm{~Hz}, J_{3,4}=4.5 \mathrm{~Hz}, J_{4, \mathrm{~F}}=21.6 \mathrm{~Hz}, 4-\mathrm{H}\right), 4.11(\mathrm{dd}, 1$ $\left.\mathrm{H}, J_{2,3}=2.1 \mathrm{~Hz}, J_{2, \mathrm{~F}}=16.9 \mathrm{~Hz}, 2-\mathrm{H}\right), 3.90\left(\mathrm{dd}, 1 \mathrm{H}, J_{5,4}=3.0 \mathrm{~Hz}, J_{5,5}=12.3 \mathrm{~Hz}, 5-\mathrm{H}\right), 3.76(\mathrm{dd}$, $\left.1 \mathrm{H}, J_{5}, 4=3.9 \mathrm{~Hz}, J_{5^{\prime}, 5}=12.3 \mathrm{~Hz}, 5^{\prime}-\mathrm{H}\right), 3.39\left(\mathrm{~s}, 3 \mathrm{H},-\mathrm{OCH}_{3}\right) ;{ }^{13} \mathrm{C}-\mathrm{NMR}\left(75 \mathrm{MHz}, \mathrm{CDCl}_{3}\right)$ $\delta 136.8,128.5,128.1,127.9,107.1(\mathrm{~d}, J=5.5 \mathrm{~Hz}), 94.8(\mathrm{~d}, J=185.3 \mathrm{~Hz}), 86.5(\mathrm{~d}, J=24.2 \mathrm{~Hz})$, $82.2(\mathrm{~d}, J=26.9 \mathrm{~Hz}), 72.0,61.6(\mathrm{~d}, J=4.9 \mathrm{~Hz}), 60.3,55.0 ;{ }^{19} \mathrm{~F}-\mathrm{NMR}\left(282 \mathrm{MHz}, \mathrm{CDCl}_{3}\right) \delta-$ 
$192.3\left(\mathrm{ddd}, J_{\mathrm{F}, 4}=22.0 \mathrm{~Hz}, J_{\mathrm{F}, 3}=53.9 \mathrm{~Hz}, J_{\mathrm{F}, 2}=16.9 \mathrm{~Hz}\right)$. HRMS $(\mathrm{CI})$ cald for $\mathrm{C}_{13} \mathrm{H}_{18} \mathrm{FO}_{4}$ 257.1189; found 257.1182.

Methyl 2-O-Benzyl-3,5-dideoxy-3-fluoro- $\alpha$-D-arabinofuranoside $(\mathbf{2 1})$. To a cooled $\left(0{ }^{\circ} \mathrm{C}\right)$ solution of compound $20(0.993 \mathrm{~g}, 3.87 \mathrm{mmol})$ in $13 \mathrm{~mL}$ of anhydrous methylene chloride was added pyridine ( $950 \mu \mathrm{L}, 3 \mathrm{eq}$.) followed by dropwise addition of trifluoromethanesulfonic anhydride (990 $\mu \mathrm{L}, 1.5$ eq.). The reaction was stirred for $30 \mathrm{~min}$ and then mixed with $40 \mathrm{~mL}$ of 1 $\mathrm{N} \mathrm{HCl}$. The organic phase was collected and the aqueous phase was re-extracted with methylene chloride $(2 \times 50 \mathrm{~mL})$. The organic extracts were pooled, dried over magnesium sulfate, and concentrated in vacuo. The crude triflate was dissolved in $13 \mathrm{~mL}$ of acetonitrile, to which was added sodium borohydride (585 $\mathrm{mg}, 4$ eq.). The suspension was stirred overnight at room temperature and quenched with $50 \mathrm{~mL}$ of $1 \mathrm{~N} \mathrm{HCl}$. After stirring for $15 \mathrm{~min}$, the mixture was concentrated in vacuo. The residue was dissolved with methylene chloride and washed with $1 \mathrm{~N}$ $\mathrm{HCl}$. The organic phase was collected and the aqueous phase was re-extracted with methylene chloride $(2 \times 50 \mathrm{~mL})$. The organic extracts were pooled, dried over magnesium sulfate, and concentrated in vacuo. Silica gel chromatography (5:1 hexanes-ethyl acetate) of the crude products afforded 21 as a syrup (998 mg, 85\%). ${ }^{1} \mathrm{H}-\mathrm{NMR}\left(300 \mathrm{MHz}, \mathrm{CDCl}_{3}\right) \delta$ 7.40-7.24 (m, 5 H, Ph), $4.90\left(\mathrm{~d}, 1 \mathrm{H}, J_{1,2}=1.2 \mathrm{~Hz}, 1-\mathrm{H}\right), 4.64(\mathrm{~d}, 1 \mathrm{H}, J=11.7 \mathrm{~Hz},-\mathrm{CH}-H-\mathrm{PH}), 4.58$ (d, $1 \mathrm{H}, J=$ $11.7 \mathrm{~Hz},-\mathrm{CH}-H-\mathrm{PH}), 4.58\left(\mathrm{dd}, J_{3,2}=3.0 \mathrm{~Hz}, J_{3,4}=5.7 \mathrm{~Hz}, J_{3, \mathrm{~F}}=53.9 \mathrm{~Hz}, 3-\mathrm{H}\right), 4.26\left(\mathrm{ddd}, J_{3,4}=\right.$ $\left.5.7 \mathrm{~Hz}, J_{4,5}=6.3 \mathrm{~Hz}, J_{4, \mathrm{~F}}=18.3 \mathrm{~Hz}, 4-\mathrm{H}\right), 4.09\left(\mathrm{ddd}, 1 \mathrm{H}, J_{2,1}=1.2 \mathrm{~Hz}, J_{2,3}=3.0 \mathrm{~Hz}, J_{2, \mathrm{~F}}=17.9\right.$ $\mathrm{Hz}, 2-\mathrm{H}), 3.39$ (s, $\left.3 \mathrm{H},-\mathrm{OCH}_{3}\right), 1.38\left(\mathrm{~d}, 3 \mathrm{H}, J=6.3 \mathrm{~Hz},-\mathrm{CH}_{3}\right) ;{ }^{13} \mathrm{C}-\mathrm{NMR}\left(75 \mathrm{MHz}, \mathrm{CDCl}_{3}\right)$ $\delta 137.1,128.5,128.0,127.8,107.0(\mathrm{~d}, J=7.2 \mathrm{~Hz}), 100.3(\mathrm{~d}, J=186.4 \mathrm{~Hz}), 87.5(\mathrm{~d}, J=23.6 \mathrm{~Hz})$ $76.6(\mathrm{~d}, J=26.4 \mathrm{~Hz}), 72.1,54.9,18.1(\mathrm{~d}, J=3.3 \mathrm{~Hz}) ;{ }^{19} \mathrm{~F}-\mathrm{NMR}\left(282 \mathrm{MHz}, \mathrm{CDCl}_{3}\right) \delta-193.0$ $\left(\mathrm{ddd}, J_{\mathrm{F}, 3}=53.9 \mathrm{~Hz}, J_{\mathrm{F}, 4}=18.3 \mathrm{~Hz}, J_{\mathrm{F}, 2}=17.9 \mathrm{~Hz}\right)$. HRMS $(\mathrm{CI})$ cald for $\mathrm{C}_{13} \mathrm{H}_{18} \mathrm{FO}_{3} 239.1083$; found 239.1084 . 
3-Deoxy-3-fluoro-4-O-benzyl-D-xylitol (23). Compound 21 (0.4 g, 1.79 mmol) was dissolved in $7.6 \mathrm{~mL}$ of $p$-dioxane and $2.53 \mathrm{~mL}$ of $3 \mathrm{~N} \mathrm{HCl}$ was added. The solution was heated at reflux for $5 \mathrm{~h}$, then poured into $20 \mathrm{~mL}$ of saturated sodium bicarbonate and extracted with ethyl acetate $(3 \times 25 \mathrm{~mL})$. The combined organic phases were dried over magnesium sulfate and concentrated in vacuo. Purification by silica gel chromatography (5:1 hexanes-ethyl acetate) afforded 22 as a light yellow syrup (0.3 g, $1.33 \mathrm{mmol}, 74 \%)$. This hemiacetal (22) was dissolved in $8.5 \mathrm{~mL}$ of HPLC grade $\mathrm{MeOH}$. To this stirred solution was added $99 \mathrm{mg}$ of sodium borohydride (2 eq.). The reaction was stirred at room temperature for $2 \mathrm{~h}$, then quenched with $10 \mathrm{~mL}$ of $1 \mathrm{~N} \mathrm{HCl}$ for $30 \mathrm{~min}$. The mixture was concentrated in vacuo to remove methanol then diluted with $10 \mathrm{~mL}$ of water. The solution was extracted with ethyl acetate $(4 \times 20 \mathrm{~mL})$. The organic phases were pooled and dried over magnesium sulfate, and concentrated in vacuo. The resulting diol, 23, was obtained in 64\% yield (0.26 g). ${ }^{1} \mathrm{H}-\mathrm{NMR}\left(300 \mathrm{MHz}, \mathrm{CDCl}_{3}\right) \delta$ 7.38-7.28 (m, $\left.5 \mathrm{H}, \mathrm{Ph}\right), 4.70(\mathrm{~s}, 2$ $\left.\mathrm{H},-\mathrm{CH}_{2}-\mathrm{Ph}\right), 4.33\left(\mathrm{ddd}, 1 \mathrm{H}, J_{3,2}=3.6 \mathrm{~Hz}, J_{3,4}=6.9 \mathrm{~Hz}, J_{3, \mathrm{~F}}=46.3 \mathrm{~Hz}, 3-\mathrm{H}\right) ; 4.10-3.90(\mathrm{~m}, 1 \mathrm{H}$, 2-H), 3.82-3.68 (m, $3 \mathrm{H}, 4-\mathrm{H}, 5-\mathrm{H}, 5-\mathrm{H}), 1.25\left(\mathrm{~d}, 3 \mathrm{H}, J_{1,2}=2.2 \mathrm{~Hz}, J_{1, \mathrm{~F}}=6.4 \mathrm{~Hz},-\mathrm{CH}_{3}\right) ;{ }^{13} \mathrm{C}-$ NMR (75 MHz, $\left.\mathrm{CDCl}_{3}\right) \delta$ 137.7, 128.6, 128.1, $95.2(\mathrm{~d}, J=177.6 \mathrm{~Hz}), 77.8(\mathrm{~d}, J=9.4 \mathrm{~Hz}), 73.1$, $66.0(\mathrm{~d}, J=25.2 \mathrm{~Hz}), 60.9(\mathrm{~d}, J=6.4 \mathrm{~Hz}), 19.1(\mathrm{~d}, J=3.9 \mathrm{~Hz}) ;{ }^{19} \mathrm{~F}-\mathrm{NMR}\left(282 \mathrm{MHz}, \mathrm{CDCl}_{3}\right) \delta-$ 202.8 (ddd, $J=8.5,23.4,45.9 \mathrm{~Hz}$ ). HRMS (CI) cald for $\mathrm{C}_{12} \mathrm{H}_{18} \mathrm{FO}_{3}$ 229.1240; found 229.1244.

3-Deoxy-3-fluoro-4-O-benzyl-5-O-benzoyl-D-xylitol (24). Compound 23 (0.18 g, 0.79 mmol) was dissolved in $2.5 \mathrm{~mL}$ of pyridine. To this solution was added benzoyl chloride $(110 \mu \mathrm{L}$, $0.95 \mathrm{mmol}, 1.2$ eq.), and the mixture was stirred overnight at room temperature. The reaction was quenched with $0.5 \mathrm{~mL}$ of water and the solvents removed in vacuo. To the residue was added $10 \mathrm{~mL}$ of saturated sodium bicarbonate, and the resulting mixture extracted with ethyl acetate $(3 \times 10 \mathrm{~mL})$. The combined organic layers were dried over magnesium sulfate and concentrated in vacuo. After silica gel chromatography (3:1 hexanes-ethyl acetate), compound 
24 was isolated as a yellow gum $(0.21 \mathrm{~g}, 80 \%) .{ }^{1} \mathrm{H}-\mathrm{NMR}\left(300 \mathrm{MHz}, \mathrm{CDCl}_{3}\right) \delta 8.06-8.00(\mathrm{~m}, 2$ H, Ph), 7.61-7.54 (m, 1 H, Ph), 7.40-7.26 (m, 7 H, Ph), 4.84 (d, 1 H, $J=11.1 \mathrm{~Hz},-\mathrm{CH}-H-\mathrm{Ph})$, $4.68(\mathrm{~d}, 1 \mathrm{H}, J=11.1 \mathrm{~Hz},-\mathrm{CH}-H-\mathrm{Ph}), 4.64-4.52\left(\mathrm{~m}, 2 \mathrm{H}, 5-\mathrm{H}, 5^{\prime}-\mathrm{H}\right) ; 4.31\left(\mathrm{dd}, 1 \mathrm{H}, J_{3,4}=2.7 \mathrm{~Hz}\right.$, $\left.J_{3,2}=7.8 \mathrm{~Hz}, J_{3, \mathrm{~F}}=45.9 \mathrm{~Hz}, 3-\mathrm{H}\right), 4.18-4.02(\mathrm{~m}, 2 \mathrm{H}, 2-\mathrm{H}, 4-\mathrm{H}), 1.92\left(\mathrm{~d}, 1 \mathrm{H}, J_{\mathrm{OH}, 2}=5.1 \mathrm{~Hz},-\right.$ $\mathrm{OH}), 1.28\left(\mathrm{dd}, 3 \mathrm{H}, J_{1,2}=2.1 \mathrm{~Hz}, J_{1, \mathrm{~F}}=6.3 \mathrm{~Hz},-\mathrm{CH}_{3}\right) ;{ }^{13} \mathrm{C}-\mathrm{NMR}\left(75 \mathrm{MHz}, \mathrm{CDCl}_{3}\right)$ $\delta 166.2,137.4,133.2,129.6,128.6,128.4,128.3,128.2,94.4(\mathrm{~d}, J=180.3 \mathrm{~Hz}), 74.2(\mathrm{~d}, J=18.6$ Hz), 73.1, $65.4(\mathrm{~d}, J=26.1 \mathrm{~Hz}), 63.0(\mathrm{~d}, J=6.6 \mathrm{~Hz}), 19.5(\mathrm{~d}, J=2.7 \mathrm{~Hz}) ;{ }^{19} \mathrm{~F}-\mathrm{NMR}(282 \mathrm{MHz}$ $\mathrm{CDCl}_{3}$ ) $\delta-205.3$ (ddd, $J=6.3,24.6,45.9 \mathrm{~Hz}$ ). HRMS (CI) cald for $\mathrm{C}_{19} \mathrm{H}_{22} \mathrm{FO}_{4} 333.1502$; found 333.1504 .

3-Deoxy-3-fluoro-4-O-benzyl-5-O-benzoyl-D-xylulose (25). Oxalyl chloride (0.11 mL, 2 eq.) was dissolved in $5 \mathrm{~mL}$ of anhydrous methylene chloride and cooled to $-60{ }^{\circ} \mathrm{C}$. To this solution was added $0.18 \mathrm{~mL}$ of anhydrous DMSO that had been previously dried over $4 \AA$ molecular sieves. After stirring for $15 \mathrm{~min}$, compound $\mathbf{2 4}$ (dissolved in $2 \times 0.75 \mathrm{~mL}$ anhydrous methylene chloride) was added to the cold mixture. After $5 \mathrm{~min}$ at $-60{ }^{\circ} \mathrm{C}$, the reaction was warmed up to $40{ }^{\circ} \mathrm{C}$ and stirred for $1 \mathrm{~h}$, at which point diisopropylethylamine $(0.66 \mathrm{~mL}, 6$ eq. $)$ was added. The reaction was stirred for $10 \mathrm{~min}$ and then washed with $20 \mathrm{~mL}$ of $1 \mathrm{~N} \mathrm{HCl}$. The aqueous layer was re-extracted with methylene chloride $(2 \times 20 \mathrm{~mL})$, and the combined organic layers were dried over magnesium sulfate and concentrated in vacuo. Silica gel chromatography (1:1 hexanesethyl acetate) of the crude products gave 25 as a clear syrup (0.16 g, 77\%). ${ }^{1} \mathrm{H}-\mathrm{NMR}$ (300 MHz, $\left.\mathrm{CDCl}_{3}\right) \delta$ 8.02-7.96 (m, $\left.2 \mathrm{H}\right), 7.60-7.52(\mathrm{~m}, 1 \mathrm{H}), 7.47-7.38(\mathrm{~m}, 2 \mathrm{H}), 7.36-7.22(\mathrm{~m}, 5 \mathrm{H}, \mathrm{PhHs})$, $4.85\left(\mathrm{dd}, 1 \mathrm{H}, J_{3,4}=2.0 \mathrm{~Hz}, J_{3, \mathrm{~F}}=48.8 \mathrm{~Hz}, 3-\mathrm{H}\right), 4.69$ (d, $1 \mathrm{H}, J=11.4$, -CH- $\left.H-\mathrm{Ph}\right), 4.59$ (ddd, 1 $\left.\mathrm{H}, J_{5, \mathrm{~F}}=1.2 \mathrm{~Hz}, J_{5,4}=6.0 \mathrm{~Hz}, J_{5,5^{\prime}}=11.4 \mathrm{~Hz}, 5-\mathrm{H}\right), 4.53(\mathrm{~d}, 1 \mathrm{H}, J=11.4,-\mathrm{CH}-H-\mathrm{Ph}), 4.48(\mathrm{dd}$, $\left.1 \mathrm{H}, J_{5^{\prime}, 4}=7.2 \mathrm{~Hz}, J_{5^{\prime}, 5}=11.4 \mathrm{~Hz}, 5^{\prime}-\mathrm{H}\right), 4.25\left(\mathrm{dddd}, 1 \mathrm{H}, J_{4,3}=2.0 \mathrm{~Hz}, J_{4,5}=6.0 \mathrm{~Hz}, J_{4,5}=7.2\right.$ 
$\left.\mathrm{Hz}, J_{4, \mathrm{~F}}=27.3 \mathrm{~Hz}, 4-\mathrm{H}\right), 2.31\left(\mathrm{~s}, 3 \mathrm{H}, J_{1, \mathrm{~F}}=5.1 \mathrm{~Hz},-\mathrm{CH}_{3}\right) ;{ }^{13} \mathrm{C}-\mathrm{NMR}\left(75 \mathrm{MHz}, \mathrm{CDCl}_{3}\right)$ $\delta 165.9,137.0,133.3,129.6,129.4,128.5,128.4,128.1,128.0,94.4(\mathrm{~d}, J=194.1 \mathrm{~Hz}), 76.6(\mathrm{~d}, J$ $=18.2 \mathrm{~Hz}), 73.8,61.8(\mathrm{~d}, J=6.6 \mathrm{~Hz}), 27.6 ;{ }^{19} \mathrm{~F}-\mathrm{NMR}\left(282 \mathrm{MHz}, \mathrm{CDCl}_{3}\right) \delta-206.6(\mathrm{ddd}, J=5.1$, 27.3, 48.8 Hz). HRMS (CI) cald for $\mathrm{C}_{19} \mathrm{H}_{20} \mathrm{FO}_{4} 331.1346$; found 331.1349 .

2-(1,3-Dioxane)-3-deoxy-3-fluoro-4-O-benzyl-5-O-benzoyl-D-xylulose (26). To a solution of $25(0.15 \mathrm{~g}, 0.45 \mathrm{mmol})$ in $7.5 \mathrm{~mL}$ of anhydrous benzene was added $2.5 \mathrm{~mL}$ of 1,3-propanediol followed by $p$-toluenesulfonic acid monohydrate $(8.3 \mathrm{mg}, 0.04 \mathrm{mmol}, 0.1 \mathrm{eq}$.$) . The reaction was$ heated at reflux overnight under Dean-Stark conditions, then cooled and washed with $20 \mathrm{~mL}$ of saturated sodium bicarbonate. The aqueous layer was re-extracted with ethyl acetate $(3 \times$ $20 \mathrm{~mL}$ ), and the combined organic layers dried over magnesium sulfate, and concentrated in vacuo. After silica gel chromatography (3:1 hexanes-ethyl acetate), the desired product $\mathbf{2 6}$ was isolated as a gum $(0.147 \mathrm{~g}, 84 \%) .{ }^{1} \mathrm{H}-\mathrm{NMR}\left(300 \mathrm{MHz}, \mathrm{CDCl}_{3}\right) \delta 8.06-8.00(\mathrm{~m}, 2 \mathrm{H})$, 7.59-7.52 (m, $1 \mathrm{H})$, 7.46-7.21 (m, $2 \mathrm{H}), 7.36-7.22$ (m, 5 H, PhHs), 4.78 (d, $1 \mathrm{H}, J=11.4$, -CH- $H-\mathrm{Ph}), 4.72$ $(\mathrm{d}, 1 \mathrm{H}, J=11.4,-\mathrm{CH}-H-\mathrm{Ph}), 4.68\left(\mathrm{dd}, 1 \mathrm{H}, J_{5,4}=4.5 \mathrm{~Hz}, J_{5,5}=11.4 \mathrm{~Hz}, 5-\mathrm{H}\right), 4.51(\mathrm{dd}, 1 \mathrm{H}$, $\left.J_{5^{\prime}, 4}=6.3 \mathrm{~Hz}, J_{5^{\prime}, 5}=11.4 \mathrm{~Hz}, 5^{\prime}-\mathrm{H}\right), 4.49\left(\mathrm{dd}, 1 \mathrm{H}, J_{3,4}=5.4 \mathrm{~Hz}, J_{3, \mathrm{~F}}=46.1 \mathrm{~Hz}, 3-\mathrm{H}\right), 4.19$ (dddd, $\left.1 \mathrm{H}, J_{4,3}=5.4 \mathrm{~Hz}, J_{4,5}=4.5 \mathrm{~Hz}, J_{4,5}=6.3 \mathrm{~Hz}, J_{4, \mathrm{~F}}=18.3 \mathrm{~Hz}, 4-\mathrm{H}\right), 4.10-3.93\left(\mathrm{~m}, 2 \mathrm{H},-\mathrm{OCH}_{2^{-}}\right)$, $1.59\left(\mathrm{~s}, 3 \mathrm{H}, J_{1, \mathrm{~F}}=3.3 \mathrm{~Hz},-\mathrm{CH}_{3}\right) ;{ }^{13} \mathrm{C}-\mathrm{NMR}\left(75 \mathrm{MHz}, \mathrm{CDCl}_{3}\right) \delta 166.3,138.1,132.9,130.0$, 129.6, 128.3, 128.2, 128.0, 127.6, $98.2(\mathrm{~d}, J=23.4 \mathrm{~Hz}), 94.7(\mathrm{~d}, J=183.0 \mathrm{~Hz}), 75.6(\mathrm{~d}, J=18.2$ Hz), 73.9, $64.1(\mathrm{~d}, J=8.2 \mathrm{~Hz}), 59.7,59.5,25.2,15.3(\mathrm{~d}, J=4.3 \mathrm{~Hz}) ;{ }^{19} \mathrm{~F}-\mathrm{NMR}(282 \mathrm{MHz}$, $\mathrm{CDCl}_{3}$ ) $\delta$-206.6 (ddd, $J=3.3,18.3,46.1 \mathrm{~Hz}$ ). HRMS (CI) cald for $\mathrm{C}_{22} \mathrm{H}_{26} \mathrm{FO}_{5} 389.1764$; found 389.1766.

2-(1,3-Dioxane)-3-deoxy-3-fluoro-4-O-benzyl-D-xylulose (27). Compound 26 was dissolved in $3 \mathrm{~mL}$ of HPLC grade methanol $(137 \mathrm{mg}, 0.35 \mathrm{mmol})$. To this solution was added $2.8 \mathrm{M}$ 
sodium methoxide/methanol ( $31 \mu \mathrm{L}, 0.25$ eq.) and the reaction was stirred at room temperature for $4 \mathrm{~h}$. It was then neutralized with successive additions of concentrated sulfuric acid and triethylamine, and concentrated in vacuo. The desired product was purified by silica gel chromatography (1:1 ethyl acetate-hexanes) to give 27 as a clear gum $(77.7 \mathrm{mg}, 77 \%) .{ }^{1} \mathrm{H}-\mathrm{NMR}$ (300 MHz, $\left.\mathrm{CDCl}_{3}\right) \delta$ 7.38-7.23 (m, $\left.5 \mathrm{H}, \mathrm{PhHs}\right), 4.78$ (d, $1 \mathrm{H}, J=11.4$, -CH- $\left.H-\mathrm{Ph}\right), 4.61$ (d, $1 \mathrm{H}$, $J=11.4,-\mathrm{CH}-H-\mathrm{Ph}), 4.44\left(\mathrm{dd}, 1 \mathrm{H}, J_{3,4}=6.9 \mathrm{~Hz}, J_{3, \mathrm{~F}}=46.2 \mathrm{~Hz}, 3-\mathrm{H}\right), 4.02\left(\mathrm{dd}, 1 \mathrm{H}, J_{5,4}=3.0\right.$ $\left.\mathrm{Hz}, J_{5,5}=11.7 \mathrm{~Hz}, J_{5, \mathrm{~F}}=17.1 \mathrm{~Hz}, 5-\mathrm{H}\right), 4.00\left(\mathrm{dd}, 1 \mathrm{H}, J_{5^{\prime}, 4}=3.0 \mathrm{~Hz}, J_{5^{\prime}, 5}=11.7 \mathrm{~Hz}, J_{5^{\prime}, \mathrm{F}}=17.1\right.$ $\left.\mathrm{Hz}, 5^{\prime}-\mathrm{H}\right), 3.92-3.72\left(\mathrm{~m}, 5 \mathrm{H}, 2 \times-\mathrm{OCH}_{2-}, 4-\mathrm{H}\right), 2.36$ (s, $\left.1 \mathrm{H},-\mathrm{OH}\right), 2.04-1.87$ (m, $1 \mathrm{H},-\mathrm{CH}-\mathrm{H}-$ ), $1.54\left(\mathrm{~d}, 3 \mathrm{H}, J_{1, \mathrm{~F}}=3.3 \mathrm{~Hz},-\mathrm{CH}_{3}\right), 1.50-1.40(\mathrm{~m}, 1 \mathrm{H},-\mathrm{CH}-\mathrm{H}-) ;{ }^{13} \mathrm{C}-\mathrm{NMR}\left(75 \mathrm{MHz}, \mathrm{CDCl}_{3}\right)$ $\delta 138.3,128.3,128.0,127.7,98.2(\mathrm{~d}, J=23.6 \mathrm{~Hz}), 95.2(\mathrm{~d}, J=180.8 \mathrm{~Hz}), 78.6(\mathrm{~d}, J=17.6 \mathrm{~Hz})$ $73.8(\mathrm{~d}, J=2.7 \mathrm{~Hz}), 62.0(\mathrm{~d}, J=8.3 \mathrm{~Hz}), 59.7,59.5,25.1,15.7(\mathrm{~d}, J=4.4 \mathrm{~Hz}) ;{ }^{19} \mathrm{~F}-\mathrm{NMR}(282$ $\mathrm{MHz}, \mathrm{CDCl}_{3}$ ) $\delta$-203.0 (ddd, $J=3.3,17.1,46.2 \mathrm{~Hz}$ ). HRMS (CI) cald for $\mathrm{C}_{15} \mathrm{H}_{22} \mathrm{FO}_{4}$ 285.1502; found 285.1511 .

Dimethyl 2-(1,3-Dioxane)-3-deoxy-3-fluoro-4-O-benzyl-D-xylulose-5-phosphate (28). To a solution of compound 27 in $3 \mathrm{~mL}$ of anhydrous methylene chloride were added trimethyl phosphite (68 $\mu \mathrm{L}, 2.1$ eq.), 2,6-lutidine ( $57 \mu \mathrm{L}, 1.8$ eq.), and tellurium tetrachloride (100 mg, 1.4 eq.). The mixture was stirred at room temperature for $90 \mathrm{~min}$, then filtered through Celite 545, and concentrated in vacuo. After silica gel chromatography (1:1 ethyl acetate-hexanes), the desired product 28 was isolated as a light-yellow gum (90 mg, 84\%). ${ }^{1} \mathrm{H}-\mathrm{NMR}$ (300 MHz, $\left.\mathrm{CDCl}_{3}\right) \delta$ 7.40-7.24 (m, $\left.5 \mathrm{H}, \mathrm{PhHs}\right), 4.74$ (d, $1 \mathrm{H}, J=11.1$, -CH- $H$-Ph), 4.68 (d, $1 \mathrm{H}, J=11.4$, CH- $H$-Ph), $4.42\left(\mathrm{dd}, 1 \mathrm{H}, J_{3,4}=4.9 \mathrm{~Hz}, J_{3, \mathrm{~F}}=46.0 \mathrm{~Hz}, 3-\mathrm{H}\right), 4.37$ (ddd, $1 \mathrm{H}, J=4.9 \mathrm{~Hz}, J=6.6$ $\left.\mathrm{Hz}, J_{5,5}=10.8 \mathrm{~Hz}, 5-\mathrm{H}\right), 4.20-3.80\left(\mathrm{~m}, 6 \mathrm{H}, \mathrm{H}-4,5\right.$ '-H, $\left.2 \times-\mathrm{OCH}_{2}-\right), 3.76\left(\mathrm{~s}, 3 \mathrm{H}, \mathrm{OCH}_{3}\right), 3.72$ (s, $\left.3 \mathrm{H}, \mathrm{OCH}_{3}\right), 2.06-1.90(\mathrm{~m}, 1 \mathrm{H},-\mathrm{CH}-H-), 1.56\left(\mathrm{~d}, 3 \mathrm{H}, J_{1, \mathrm{~F}}=3.3 \mathrm{~Hz},-\mathrm{CH}_{3}\right), 1.52-1.43(\mathrm{~m}, 1$ $\mathrm{H},-\mathrm{CH}-H-) ;{ }^{13} \mathrm{C}-\mathrm{NMR}\left(63 \mathrm{MHz}, \mathrm{CDCl}_{3}\right) \delta 137.9,128.2,128.0,127.6,98.1(\mathrm{~d}, J=24.0 \mathrm{~Hz})$, 
$93.7(\mathrm{~d}, J=182.8 \mathrm{~Hz}), 76.2(\mathrm{~d}, J=7.9 \mathrm{~Hz}), 75.9(\mathrm{~d}, J=8.0 \mathrm{~Hz}), 66.4(\mathrm{dd}, J=5.6,7.7 \mathrm{~Hz}), 59.7$, $59.3,54.2(\mathrm{dd}, J=2.6,5.7 \mathrm{~Hz}), 25.2,15.4(\mathrm{~d}, J=5.0 \mathrm{~Hz}) ;{ }^{19} \mathrm{~F}-\mathrm{NMR}\left(282 \mathrm{MHz}, \mathrm{CDCl}_{3}\right) \delta-206.6$ (ddd, $J=2.8,18.0,46.0 \mathrm{~Hz}) ;{ }^{19} \mathrm{P}-\mathrm{NMR}\left(121 \mathrm{MHz}, \mathrm{CDCl}_{3}\right) \delta 2.34$. HRMS $(\mathrm{CI})$ cald for $\mathrm{C}_{17} \mathrm{H}_{27} \mathrm{FO}_{7} \mathrm{P} 393.1478$; found 393.1466.

3-Deoxy-3-fluoro-D-xylulose-5-phosphate (6). To a solution of compound 28 in $650 \mu \mathrm{L}$ of deuterated chloroform was added trimethylsilyl bromide ( $21 \mu \mathrm{L}, 2.2$ eq. $)$. After $90 \mathrm{~min},{ }^{1} \mathrm{H}-$ NMR showed the reaction was complete. The solution was concentrated to half its volume and diluted with $650 \mu \mathrm{L}$ of water. This stirred for 90 min before it was concentrated in vacuo and dissolved with $700 \mu \mathrm{L}$ of methanol and $100 \mu \mathrm{L}$ of water. To this solution was added $10 \%$ palladium on carbon ( $8 \mathrm{mg}, 0.1$ eq.). The suspension was stirred under hydrogen gas overnight, filtered through Celite 545, and concentrated in vacuo. The reaction was neutralized with solid sodium bicarbonate and lyophilized to yield a white, foamy residue. This residue was dissolved in minimum amount of water and methanol and purified by cellulose chromatography (Whatman CF-11) (9:1 tetrahydrofuran-0.1\% aqueous trifluoroacetic acid). Fractions containing the desired product were concentrated in vacuo to remove tetrahydrofuran then lyophilized to give $\mathbf{6}$ as a white foam $(9.8 \mathrm{mg}, 62 \%) .{ }^{1} \mathrm{H}-\mathrm{NMR}\left(500 \mathrm{MHz}, \mathrm{D}_{2} \mathrm{O}\right) \delta 5.15\left(\mathrm{dd}, 1 \mathrm{H}, J_{3,4}=1.8 \mathrm{~Hz}, J_{3, \mathrm{~F}}=47.8\right.$ $\mathrm{Hz}, 3-\mathrm{H}), 4.31\left(\mathrm{ddt}, J_{4,3}=1.8 \mathrm{~Hz}, J_{4,5}=6.8 \mathrm{~Hz}, J_{4, \mathrm{~F}}=29.2 \mathrm{~Hz}, 4-\mathrm{H}\right), 3.95-3.83\left(\mathrm{~m}, 2 \mathrm{H}, 5-\mathrm{H}_{2}\right)$, $2.25\left(\mathrm{~d}, 3 \mathrm{H}, J_{1, \mathrm{~F}}=3.8 \mathrm{~Hz},-\mathrm{CH}_{3}\right) ;{ }^{13} \mathrm{C}-\mathrm{NMR}\left(126 \mathrm{MHz}, \mathrm{D}_{2} \mathrm{O}\right) \delta 210.2(\mathrm{~d}, J=22.0 \mathrm{~Hz}), 94.8(\mathrm{~d}, J$ $=187.9 \mathrm{~Hz}), 69.8(\mathrm{dd}, J=8.2,18.6 \mathrm{~Hz}), 64.5(\mathrm{t}, J=5.5 \mathrm{~Hz}), 26.4 ;{ }^{19} \mathrm{~F}-\mathrm{NMR}\left(282 \mathrm{MHz}, \mathrm{D}_{2} \mathrm{O}\right) \delta-$

210.3 (ddd, $J=3.8 .29 .2,47.8 \mathrm{~Hz}) ;{ }^{31} \mathrm{P}-\mathrm{NMR}\left(121 \mathrm{MHz}, \mathrm{D}_{2} \mathrm{O}\right) \delta 1.2$. HRMS (CI) cald for $\mathrm{C}_{5} \mathrm{H}_{11} \mathrm{FO}_{6} \mathrm{P}$ 215.0121; found 215.0120.

Synthesis of 4-Deoxy-4-fluoro-D-xylulose-5-phosphate (4-Fluoro-DXP) (7). 1,2Isopropylidene-3-O-benzyl-D-ribofuranoside $\quad(\mathbf{3 0}) . \quad$ 1,2-O-Isopropylidene-5-O-tert-butyldiphenylsilyl- $\alpha$-D-ribofuranose $(29)^{26}(56 \mathrm{~g}, 66 \mathrm{mmol})$ was dissolved in $260 \mathrm{~mL}$ of $\mathrm{N}, \mathrm{N}-$ 
dimethylformamide and cooled to $4{ }^{\circ} \mathrm{C}$. To this solution was added sodium hydride $(5.78 \mathrm{~g}$, $60 \%, 1.1$ eq.) and the mixture stirred for $5 \mathrm{~min}$. Benzyl bromide (17.2 mL, 1.1 eq.) was then added, and the mixture allowed to warm gradually to room temperature overnight. The reaction was quenched with $1 \mathrm{~N} \mathrm{HCl}(50 \mathrm{~mL})$ and the mixture stirred for $15 \mathrm{~min}$, then concentrated in vacuo. Water $(100 \mathrm{~mL})$ was added to the residue and the mixture extracted with $3 \times 100 \mathrm{~mL}$ of methylene chloride. The organic layers were pooled, dried over magnesium sulfate, and concentrated in vacuo. The crude product was dissolved in $600 \mathrm{~mL}$ of THF. To this solution was added tetrabutylammonium fluoride trihydrate (34 g, 1 eq.). After stirring for $1 \mathrm{~h}$ at room temperature, the solution was concentrated in vacuo and the residue purified by silica gel chromatography (1:2 hexanes-ethyl acetate) to afford 30 as a syrup $\left(24.7 \mathrm{~g}, 67 \%\right.$ overall). ${ }^{1} \mathrm{H}-$

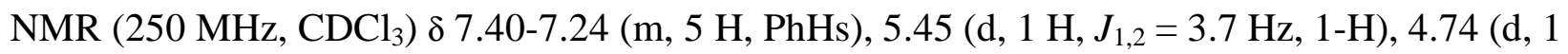
$\mathrm{H}, J=11.9 \mathrm{~Hz}, \mathrm{CH}-\mathrm{H}-\mathrm{Ph}), 4.58$ (d, $1 \mathrm{H}, J=11.9 \mathrm{~Hz}, \mathrm{CH}-\mathrm{H}-\mathrm{Ph}), 4.56$ (m, $1 \mathrm{H}, 2-\mathrm{H}), 4.10$ (dt, 1 $\left.\mathrm{H}, J_{4,5}=2.8 \mathrm{~Hz}, J_{4,3}=9.0 \mathrm{~Hz}, 4-\mathrm{H}\right), 3.94-3.60(\mathrm{~m}, 2 \mathrm{H}, 3-\mathrm{H}, 5-\mathrm{H}), 3.62\left(\mathrm{ddd}, 1 \mathrm{H}, J_{5,4}=2.8 \mathrm{~Hz}\right.$, $\left.J_{5^{\prime}, \mathrm{OH}}=8.3 \mathrm{~Hz}, J_{5,5^{\prime}}=12.5 \mathrm{~Hz}, 5^{\prime}-\mathrm{H}\right), 2.16\left(\mathrm{dd}, 1 \mathrm{H}, J_{\mathrm{OH}, 5}=4.3 \mathrm{~Hz}, J_{\mathrm{OH}, 5},=8.3 \mathrm{~Hz},-\mathrm{OH}\right), 1.60$ (s, $\left.3 \mathrm{H},-\mathrm{CH}_{3}\right), 1.35\left(\mathrm{~s}, 3 \mathrm{H},-\mathrm{CH}_{3}\right) ;{ }^{13} \mathrm{C}-\mathrm{NMR}\left(62 \mathrm{MHz}, \mathrm{CDCl}_{3}\right) \delta$ 137.4, 128.4, 128.0, 127.9, 113.0, 104.0, 78.7, 72.2, 60.4, 26.7, 26.4.

1,2-Isopropylidene-3-O-benzyl-5-deoxy- $\alpha$-D-ribofuranoside (31). Compound 30 (24.7 g, 88 mmol) was dissolved in $300 \mathrm{~mL}$ of methylene chloride and cooled to $4{ }^{\circ} \mathrm{C}$. Pyridine $(15.6 \mathrm{~mL}$, 2.2 eq.) was added, followed by trifluoromethanesulfonic anhydride (16.6 mL, 1.1 eq.). The mixture was stirred for $30 \mathrm{~min}$ then washed with $300 \mathrm{~mL}$ of $1 \mathrm{~N} \mathrm{HCl}$. The organic phase was collected and the aqueous phase was extracted with $2 \times 100 \mathrm{~mL}$ methylene chloride. The combined organic layers were dried over magnesium sulfate and concentrated in vacuo. The reddish syrup was dissolved in $350 \mathrm{~mL}$ of HPLC grade acetonitrile and cooled to $4{ }^{\circ} \mathrm{C}$. Sodium borohydride ( $8.0 \mathrm{~g}, 2.4$ eq.) was then added and the resulting mixture was stirred at room 
temperature overnight. The reaction was quenched with $100 \mathrm{~mL}$ of $1 \mathrm{~N} \mathrm{HCl}$ and the mixture stirred for $15 \mathrm{~min}$, then concentrated in vacuo. The aqueous phase was extracted with $2 \times 100$ $\mathrm{mL}$ methylene chloride, and the organic layers were pooled, dried over magnesium sulfate, and concentrated in vacuo. Silica gel chromatography (3:1 hexanes-ethyl acetate) purification afforded 31 as a syrup $(9.3 \mathrm{~g}, 40 \%) .{ }^{1} \mathrm{H}-\mathrm{NMR}\left(250 \mathrm{MHz}, \mathrm{CDCl}_{3}\right) \delta 7.40-7.24(\mathrm{~m}, 5 \mathrm{H}, \mathrm{PhHs})$, $5.45\left(\mathrm{~d}, 1 \mathrm{H}, J_{1,2}=4.0 \mathrm{~Hz}, 1-\mathrm{H}\right), 4.80(\mathrm{~d}, 1 \mathrm{H}, J=12.0 \mathrm{~Hz}, \mathrm{CH}-H-\mathrm{Ph}), 4.56(\mathrm{~d}, 1 \mathrm{H}, J=12.0 \mathrm{~Hz}$, CH-H-Ph), $4.56\left(\mathrm{~d}, 1 \mathrm{H}, J_{2,1}=4.0 \mathrm{~Hz}, 2-\mathrm{H}\right), 4.12\left(\mathrm{dq}, 1 \mathrm{H}, J_{4,5}=6.1 \mathrm{~Hz}, J_{4,3}=8.9 \mathrm{~Hz}, 4-\mathrm{H}\right), 3.32$ $\left(\mathrm{dd}, 1 \mathrm{H}, J_{3,2}=4.3 \mathrm{~Hz}, J_{3,4}=8.9 \mathrm{~Hz}, 3-\mathrm{H}\right), 1.60\left(\mathrm{~s}, 3 \mathrm{H},-\mathrm{CH}_{3}\right), 1.35\left(\mathrm{~s}, 3 \mathrm{H},-\mathrm{CH}_{3}\right), 1.26(\mathrm{~d}, 3 \mathrm{H}$, $\left.J_{1,2}=6.1 \mathrm{~Hz},-\mathrm{CH}_{3}\right) ;{ }^{13} \mathrm{C}-\mathrm{NMR}\left(62 \mathrm{MHz}, \mathrm{CDCl}_{3}\right) \delta 137.6,128.4,128.0,127.9,112.5,103.7$, $83.1,77.2,74.0,72.0,26.5,26.4,17.2$.

Methyl 2-O-Acetyl-3-O-benzyl-5-deoxy- $\alpha$-D-ribofuranoside (32). Compound 31 (9.3 g, 35.2 mmol) was dissolved in $2.5 \%$ (v/v) sulfuric acid in methanol and heated at reflux for $2 \mathrm{~h}$. The solution was then neutralized with sodium bicarbonate and concentrated in vacuo. The resulting syrup was treated with $20 \mathrm{~mL}$ of pyridine and $10 \mathrm{~mL}$ of acetic anhydride for $2 \mathrm{~h}$. The mixture was diluted with $100 \mathrm{~mL}$ of $1 \mathrm{~N} \mathrm{HCl}$ and then extracted with methylene chloride $(3 \times 100 \mathrm{~mL})$. The combined organic phases were dried over magnesium sulfate and concentrated in vacuo. Silica gel chromatography (5:1 hexanes-ethyl acetate) of the crude products afforded the desired product 32 as a mixture of alpha anomer $(1.76 \mathrm{~g}, 18 \%)$ and the beta anomer $(6.03 \mathrm{~g}, 61 \%)$. The spectral data of the $\alpha$-isomer: ${ }^{1} \mathrm{H}-\mathrm{NMR}\left(250 \mathrm{MHz}, \mathrm{CDCl}_{3}\right) \delta$ 7.36-7.24 (m, $\left.5 \mathrm{H}, \mathrm{PhHs}\right), 4.96$ (d, 1 $\left.\mathrm{H}, J_{1,2}=4.5 \mathrm{~Hz}, 1-\mathrm{H}\right), 4.86\left(\mathrm{dd}, 1 \mathrm{H}, J_{2,1}=4.5 \mathrm{~Hz}, J_{2,3}=7.0 \mathrm{~Hz}, 2-\mathrm{H}\right), 4.60(\mathrm{~d}, 1 \mathrm{H}, J=12.3 \mathrm{~Hz}$, CH- $H$-Ph), 4.50 (d, $1 \mathrm{H}, J=12.3 \mathrm{~Hz}, \mathrm{CH}-H-\mathrm{Ph}), 4.10-3.96(\mathrm{~m}, 1 \mathrm{H}, 4-\mathrm{H}), 3.54$ (dd, $1 \mathrm{H}, J_{3,4}=$ $\left.5.4 \mathrm{~Hz}, J_{3,2}=7.0 \mathrm{~Hz}, 3-\mathrm{H}\right), 3.34\left(\mathrm{~s}, 3 \mathrm{H},-\mathrm{OCH}_{3}\right), 2.18(\mathrm{~s}, 3 \mathrm{H},-\mathrm{OAc}), 1.08\left(\mathrm{~d}, 3 \mathrm{H}, J_{5,4}=6.4\right.$ $\left.\mathrm{Hz},-\mathrm{CH}_{3}\right) ;{ }^{13} \mathrm{C}-\mathrm{NMR}\left(63 \mathrm{MHz}, \mathrm{CDCl}_{3}\right) \delta 170.3,137.6,128.1,127.8,127.7,101.2,79.6,77.1$, 72.9, 71.5, 55.1, 20.5, 18.5. HRMS (CI) cald for $\mathrm{C}_{15} \mathrm{H}_{21} \mathrm{O}_{5} 279.1232$, found 279.1238. 
Methyl 3-O-Benzyl-5-deoxy- $\alpha$-D-ribofuranoside (33). Compound 32 was dissolved in $50 \mathrm{~mL}$ of HPLC grade methanol $(1.72 \mathrm{~g}, 6.14 \mathrm{mmol})$. To this solution was added $2.8 \mathrm{M}$ sodium methoxide/methanol (55 $\mu \mathrm{L}, 0.25$ eq.). The solution was stirred for $15 \mathrm{~min}$ at room temperature then neutralized with Amberlite IR-120 $\left(\mathrm{H}^{+}\right)$resin, filtered and concentrated in vacuo. Purification by silica gel chromatography (2:1 ethyl acetate-hexanes) afforded $\mathbf{3 3}$ (1.4 g) in 96\% yield. ${ }^{1} \mathrm{H}-\mathrm{NMR}\left(250 \mathrm{MHz}, \mathrm{CDCl}_{3}\right)$ 8 7.36-7.24 (m, $\left.5 \mathrm{H}, \mathrm{PhHs}\right), 4.84\left(\mathrm{~d}, 1 \mathrm{H}, J_{1,2}=4.6 \mathrm{~Hz}, 1-\mathrm{H}\right)$, $4.76(\mathrm{~d}, 1 \mathrm{H}, J=12.3 \mathrm{~Hz}, \mathrm{CH}-H-\mathrm{Ph}), 4.56$ (d, $1 \mathrm{H}, J=12.3 \mathrm{~Hz}, \mathrm{CH}-H-\mathrm{Ph}), 4.10-4.00$ (m, $2 \mathrm{H}, 3-$ H, 4-H), $3.72\left(\mathrm{~s}, 3 \mathrm{H},-\mathrm{OCH}_{3}\right), 3.72\left(\mathrm{dd}, 1 \mathrm{H}, J_{2,1}=4.6 \mathrm{~Hz}, J_{2,3}=6.9 \mathrm{~Hz}, 2-\mathrm{H}\right), 2.95(\mathrm{~s}, 1 \mathrm{H},-$ $\mathrm{OH}), 1.15\left(\mathrm{~d}, 3 \mathrm{H}, J_{5,4}=6.6 \mathrm{~Hz},-\mathrm{CH}_{3}\right) ;{ }^{13} \mathrm{C}-\mathrm{NMR}\left(63 \mathrm{MHz}, \mathrm{CDCl}_{3}\right) \delta 137.8,128.4,127.8$, 102.5, 80.4, 77.9, 72.9, 71.4, 55.2, 19.3. HRMS (CI) cald for $\mathrm{C}_{13} \mathrm{H}_{19} \mathrm{O}_{4}$ 239.1283, found 239.1275.

Methyl 2,5-Dideoxy-2-fluoro-3-O-benzyl- $\alpha$-D-arabinofuranoside (34). To a solution of compound $33(1.39 \mathrm{~g}, 5.79 \mathrm{mmol})$ in $50 \mathrm{~mL}$ of dry methylene chloride and cooled to $0{ }^{\circ} \mathrm{C}$. To this solution was added pyridine $(1.4 \mathrm{~mL}$, 3eq.) followed by trifluoromethanesulfonic anhydride $\left(1.5 \mathrm{~mL}, 1.5\right.$ eq.). The reaction mixture was stirred for $1 \mathrm{~h}$ at $4{ }^{\circ} \mathrm{C}$ then washed with $50 \mathrm{~mL}$ of saturated sodium bicarbonate. The aqueous phase was re-extracted with $50 \mathrm{~mL}$ of methylene chloride. The organic phases were combined, dried over magnesium sulfate and concentrated in vacuo. The resulting triflate was dissolved in $70 \mathrm{~mL}$ of dry THF and cooled to $4{ }^{\circ} \mathrm{C}$. To this solution was added $20 \mathrm{~mL}$ of $1 \mathrm{M}$ tetrabutylammonium fluoride, and the resulting reaction mixture was stirred for $24 \mathrm{~h}$ at $4{ }^{\circ} \mathrm{C}$. The mixture was concentrated in vacuo and purified by silica gel chromatography (5:1 hexanes-ethyl acetate) to afford the fluorinated sugar $34(0.80 \mathrm{~g}$, 56\%). ${ }^{1} \mathrm{H}-\mathrm{NMR}\left(300 \mathrm{MHz}, \mathrm{CDCl}_{3}\right) \delta$ 7.36-7.24 (m, $\left.5 \mathrm{H}, \mathrm{PhHs}\right), 4.96\left(\mathrm{~d}, 1 \mathrm{H}, J_{1, \mathrm{~F}}=12.1 \mathrm{~Hz}, 1-\right.$ H), $4.94\left(\mathrm{dd}, 1 \mathrm{H}, J_{2,3}=2.2 \mathrm{~Hz}, J_{2, \mathrm{~F}}=51.9 \mathrm{~Hz}, 2-\mathrm{H}\right), 4.71(\mathrm{~d}, 1 \mathrm{H}, J=12.0 \mathrm{~Hz}, \mathrm{CH}-H-\mathrm{Ph}), 4.66$ $(\mathrm{d}, 1 \mathrm{H}, J=12.0 \mathrm{~Hz}, \mathrm{CH}-H-\mathrm{Ph}), 4.14-3.92(\mathrm{~m}, 1 \mathrm{H}, 4-\mathrm{H}), 3.65$ (dddd, $1 \mathrm{H}, J_{3,1}=0.9 \mathrm{~Hz}, J_{3,2}=$ 
$\left.2.2 \mathrm{~Hz}, J_{3,4}=6.9 \mathrm{~Hz}, J_{3, \mathrm{~F}}=25.2 \mathrm{~Hz}, 3-\mathrm{H}\right), 3.35\left(\mathrm{~s}, 3 \mathrm{H},-\mathrm{OCH}_{3}\right), 1.30\left(\mathrm{~d}, 3 \mathrm{H}, J_{5,4}=6.3 \mathrm{~Hz},-\right.$ $\left.\mathrm{CH}_{3}\right) ;{ }^{13} \mathrm{C}-\mathrm{NMR}\left(75 \mathrm{MHz}, \mathrm{CDCl}_{3}\right) \delta$ 137.2, 128.4, 127.9, 127.8, $106.1(\mathrm{~d}, J=36.3 \mathrm{~Hz}), 100.4(\mathrm{~d}$, $J=29.9 \mathrm{~Hz}), 88.0(\mathrm{~d}, J=24.2 \mathrm{~Hz}), 77.2(\mathrm{~d}, J=5.0 \mathrm{~Hz}), 72.5,54.6,18.4 ;{ }^{19} \mathrm{~F}-\mathrm{NMR}(282 \mathrm{MHz}$, $\left.\mathrm{CDCl}_{3}\right) \delta-187.6\left(\mathrm{ddd}, J_{\mathrm{F}, 1}=12.1 \mathrm{~Hz}, J_{\mathrm{F}, 3}=25.2 \mathrm{~Hz}, J_{\mathrm{F}, 2}=51.9 \mathrm{~Hz}\right)$. HRMS (CI) cald for $\mathrm{C}_{13} \mathrm{H}_{18} \mathrm{FO}_{3} 241.1240$, found 241.1231.

3-O-Benzyl-4-deoxy-4-fluoro-D-xylitol (36). Compound $34(0.80 \mathrm{~g}, 3.33 \mathrm{mmol})$ was dissolved in $15 \mathrm{~mL}$ of $p$-dioxane. To this solution was added $5 \mathrm{~mL}$ of $3 \mathrm{~N} \mathrm{HCl}$. The reaction mixture was heated at reflux for two days, then poured into $100 \mathrm{~mL}$ of saturated sodium bicarbonate and extracted with ethyl acetate $(3 \times 100 \mathrm{~mL})$. The combined organic phases were dried over magnesium sulfate and concentrated in vacuo. Silica gel chromatography (2:1 hexanes-ethyl acetate) afforded the C-1 deprotected sugar 35 in $82 \%$ yield (0.62 g, $2.74 \mathrm{mmol})$. This intermediate product 35 was dissolved in $18 \mathrm{~mL}$ of methanol and cooled to $4{ }^{\circ} \mathrm{C}$. To this stirred solution was added $207 \mathrm{mg}$ of sodium borohydride. The reaction mixture was stirred for $90 \mathrm{~min}$ at room temperature. Water $(10 \mathrm{~mL})$ was then added and the mixture stirred for an additional $15 \mathrm{~min}$. The reaction mixture was concentrated in vacuo, diluted with $10 \mathrm{~mL}$ of water, and extracted with ethyl acetate $(3 \times 20 \mathrm{~mL})$. The combined organic layers were dried over magnesium sulfate and concentrated in vacuo. Purification by silica gel chromatography (2:1 ethyl acetate-hexanes) afforded $\mathbf{3 6}$ as a white solid (0.53 g, 70\%). ${ }^{1} \mathrm{H}-\mathrm{NMR}(300 \mathrm{MHz}$, $\left.\mathrm{CDCl}_{3}\right) \delta$ 7.36-7.26 (m, $\left.5 \mathrm{H}, \mathrm{PhHs}\right), 4.70\left(\mathrm{ddd}, 1 \mathrm{H}, J_{4,3}=4.2 \mathrm{~Hz}, J_{4,5}=9.4 \mathrm{~Hz}, J_{4, \mathrm{~F}}=47.0 \mathrm{~Hz}, 4-\right.$ H); 4.68 (d, $1 \mathrm{H}, J=10.4 \mathrm{~Hz}, \mathrm{CH}-H-\mathrm{Ph}), 4.63(\mathrm{~d}, 1 \mathrm{H}, J=10.4 \mathrm{~Hz}, \mathrm{CH}-H-\mathrm{Ph}), 4.02-3.65$ (m, 3 H, 2-H, 5-H, 5'-H), 3.56-3.42 (ddd, $\left.1 \mathrm{H}, J_{3,4}=4.2 \mathrm{~Hz}, J_{3,2}=5.8 \mathrm{~Hz}, J_{3, \mathrm{~F}}=20.1 \mathrm{~Hz}, 3-\mathrm{H}\right), 3.00(\mathrm{~s}$, $2 \mathrm{H}, 2 \times-\mathrm{OH}), 1.26\left(\mathrm{~d}, 3 \mathrm{H}, J_{1,2}=6.4 \mathrm{~Hz},-\mathrm{CH}_{3}\right) ;{ }^{13} \mathrm{C}-\mathrm{NMR}\left(75 \mathrm{MHz}, \mathrm{CDCl}_{3}\right) \delta 137.7,128.5$, 128.0, $94.0(\mathrm{~d}, J=175.0 \mathrm{~Hz}), 81.4(\mathrm{~d}, J=18.3 \mathrm{~Hz}), 74.2,66.9(\mathrm{~d}, J=5.2 \mathrm{~Hz}), 61.8(\mathrm{~d}, J=23.3$ 
$\mathrm{Hz}), 19.2 ;{ }^{19} \mathrm{~F}-\mathrm{NMR}\left(282 \mathrm{MHz}, \mathrm{CDCl}_{3}\right) \delta-194.9--199.9(\mathrm{~m})$. HRMS (CI) cald for $\mathrm{C}_{12} \mathrm{H}_{18} \mathrm{FO}_{3}$ 229.1240 , found 229.1237.

3-O-Benzyl-4-deoxy-4-fluoro-5-O-benzoyl-D-xylitol (37). To a solution of compound 36 (0.31 g, $1.4 \mathrm{mmol})$ in $5 \mathrm{~mL}$ of pyridine was added benzoyl chloride (0.19 mL, 1.2 eq.) and the solution stirred at room temperature overnight. The reaction was quenched with $5 \mathrm{~mL}$ of saturated sodium bicarbonate, and the mixture concentrated in vacuo. Ethyl acetate (25 mL) was added and the solution was washed with $25 \mathrm{~mL}$ of saturated sodium bicarbonate. The aqueous layer was re-extracted with ethyl acetate $(2 \times 25 \mathrm{~mL})$, and the pooled organic layers dried over magnesium sulfate and concentrated in vacuo. The desired product $\mathbf{3 7}$ was purified by silica gel chromatography (2:1 hexanes-ethyl acetate) and the yield was $87 \%(0.389 \mathrm{~g}) .{ }^{1} \mathrm{H}-\mathrm{NMR}(300$ $\left.\mathrm{MHz}, \mathrm{CDCl}_{3}\right) \delta$ 8.05-8.01 (m, $\left.2 \mathrm{H}\right), 7.59-7.52(\mathrm{~m}, 1 \mathrm{H}), 7.46-7.39(\mathrm{~m}, 2 \mathrm{H}), 7.37-7.25(\mathrm{~m}, 5 \mathrm{H}$, PhHs), 5.03 (ddt, $\left.1 \mathrm{H}, J_{4,3}=4.8 \mathrm{~Hz}, J_{4,5}=6.0 \mathrm{~Hz}, J_{4, \mathrm{~F}}=47.7 \mathrm{~Hz}, 4-\mathrm{H}\right) ; 4.71\left(\mathrm{~s}, 2 \mathrm{H},-\mathrm{CH}_{2}-\mathrm{Ph}\right)$, 4.61-4.57 (m, $1 \mathrm{H}, 5-\mathrm{H}), 4.53-4.50$ (m, $1 \mathrm{H}, 5$ '-H), 4.14-4.00 (m, $1 \mathrm{H}, 2-\mathrm{H}), 3.56$ (ddd, $1 \mathrm{H}, J_{3,4}=$ $\left.4.8 \mathrm{~Hz}, J_{3,2}=5.4 \mathrm{~Hz}, J_{3, \mathrm{~F}}=18.6 \mathrm{~Hz}, 3-\mathrm{H}\right), 2.26(\mathrm{~s}, 1 \mathrm{H},-\mathrm{OH}), 1.31\left(\mathrm{~d}, 3 \mathrm{H}, J_{1,2}=6.3 \mathrm{~Hz},-\mathrm{CH}_{3}\right)$; ${ }^{13} \mathrm{C}-\mathrm{NMR}\left(75 \mathrm{MHz}, \mathrm{CDCl}_{3}\right) \delta 166.2,137.5,133.2,129.6,129.5,128.5,128.4,128.0,91.1(\mathrm{~d}, J=$ $178.1 \mathrm{~Hz}), 81.0(\mathrm{~d}, J=17.6 \mathrm{~Hz}), 74.2,66.8(\mathrm{~d}, J=4.4 \mathrm{~Hz}), 63.9(\mathrm{~d}, J=24.2 \mathrm{~Hz}), 19.3 ;{ }^{19} \mathrm{~F}-\mathrm{NMR}$ $\left(282 \mathrm{MHz}, \mathrm{CDCl}_{3}\right) \delta-200.1--200.5(\mathrm{~m})$. HRMS (CI) cald for $\mathrm{C}_{19} \mathrm{H}_{22} \mathrm{FO}_{4}$ 333.1502; found 333.1504.

3-O-Benzyl-4-deoxy-4-fluoro-5-O-benzoyl-D-xylulose (38). To a cooled $\left(-60^{\circ} \mathrm{C}\right)$ solution of oxalyl chloride $(0.20 \mathrm{~mL}, 2$ eq. $)$ in $9 \mathrm{~mL}$ of anhydrous methylene chloride was added anhydrous dimethyl sulfoxide (0.32 mL, 4 eq.) and stirred for $15 \mathrm{~min}$. Compound 37 (0.373 g, $1.12 \mathrm{mmol})$ (dissolved in $2 \mathrm{~mL}$ of anhydrous methylene chloride) was then added dropwise to the cold solution and stirred for $5 \mathrm{~min}$. The solution was warmed to $-40{ }^{\circ} \mathrm{C}$ and stirred for $1 \mathrm{~h}$, after which diisopropyl ethylamine $(1.17 \mathrm{~mL}, 6$ eq.) was added. The mixture was stirred for $10 \mathrm{~min}$ 
then washed with $20 \mathrm{~mL}$ of $1 \mathrm{~N} \mathrm{HCl}$. The organic layer was collected and the aqueous layer was re-extracted with methylene chloride $(2 \times 25 \mathrm{~mL})$. The combined organic layers were dried over magnesium sulfate and concentrated in vacuo. Purification by silica gel chromatography (3:1 hexanes-ethyl acetate) afforded $38(0.294 \mathrm{~g})$ in $79 \%$ yield. ${ }^{1} \mathrm{H}-\mathrm{NMR}\left(300 \mathrm{MHz}, \mathrm{CDCl}_{3}\right) \delta 7.99$ 7.93 (m, 2 H), 7.59-7.51 (m, 1 H), 7.45-7.37 (m, 2 H), 7.36-7.24 (m, 5 H, PhHs), 5.04 (dddd, 1 $\left.\mathrm{H}, J_{4,3}=2.9 \mathrm{~Hz}, J_{4,5}=4.5 \mathrm{~Hz}, J_{4,5^{\prime}}=6.9 \mathrm{~Hz}, J_{4, \mathrm{~F}}=49.5 \mathrm{~Hz}, 4-\mathrm{H}\right) ; 4.78(\mathrm{~d}, 1 \mathrm{H}, J=11.7 \mathrm{~Hz},-\mathrm{CH}-$ $H$-Ph), $4.56\left(\mathrm{ddd}, 1 \mathrm{H}, J_{5^{\prime}, 4}=6.9 \mathrm{~Hz}, J_{5^{\prime}, 5}=12.0 \mathrm{~Hz}, J_{5^{\prime}, \mathrm{F}}=15.6 \mathrm{~Hz}, 5^{\prime}-\mathrm{H}\right), 4.45(\mathrm{~d}, 1 \mathrm{H}, J=11.7$ $\mathrm{Hz},-\mathrm{CH}-H-\mathrm{Ph}), 4.44\left(\mathrm{ddd}, 1 \mathrm{H}, J_{5,4}=4.5 \mathrm{~Hz}, J_{5,5}=12.0 \mathrm{~Hz}, J_{5, \mathrm{~F}}=23.4 \mathrm{~Hz}, 5-\mathrm{H}\right), 3.98(\mathrm{dd}, 1 \mathrm{H}$, $\left.J_{3,4}=2.9 \mathrm{~Hz}, J_{3, \mathrm{~F}}=28.2 \mathrm{~Hz}, 3-\mathrm{H}\right), 2.28\left(\mathrm{~d}, 3 \mathrm{H}, J_{1, \mathrm{~F}}=0.6 \mathrm{~Hz},-\mathrm{CH}_{3}\right) ;{ }^{13} \mathrm{C}-\mathrm{NMR}(75 \mathrm{MHz}$, $\left.\mathrm{CDCl}_{3}\right) \delta 165.8,136.1,133.2,129.6,129.2,128.6,128.4,128.3,128.2,90.6(\mathrm{~d}, J=179.8 \mathrm{~Hz})$, $82.7(\mathrm{~d}, J=19.8 \mathrm{~Hz}), 73.7,62.6(\mathrm{~d}, J=26.9 \mathrm{~Hz}), 27.4(\mathrm{~d}, J=1.7 \mathrm{~Hz}) ;{ }^{19} \mathrm{~F}-\mathrm{NMR}(282 \mathrm{MHz}$, $\left.\mathrm{CDCl}_{3}\right) \delta-201.8\left(\mathrm{dddd}, J_{5}{ }^{,} \mathrm{F}=15.6 \mathrm{~Hz}, J_{5, \mathrm{~F}}=23.4 \mathrm{~Hz}, J_{3, \mathrm{~F}}=28.2 \mathrm{~Hz}, J_{4, \mathrm{~F}}=49.5 \mathrm{~Hz},\right) . \mathrm{HRMS}$ (CI) cald for $\mathrm{C}_{19} \mathrm{H}_{20} \mathrm{FO}_{4} 331.1346$; found 331.1355.

2-(1,3-Dioxane)-3-O-benzyl-4-deoxy-4-fluoro-5-O-benzoyl-D-xylulose (39). Compound 38 $(0.273 \mathrm{~g}, 0.83 \mathrm{mmol})$ was dissolved in $6 \mathrm{~mL}$ of benzene. To this was added $2 \mathrm{~mL}$ of $1,3-$ propanediol and $p$-toluenesulfonic acid monohydrate (16 mg, 0.1 eq.). The solution was heated at reflux under a dropping funnel containing $3 \AA$ molecular sieves for $18 \mathrm{~h}$, then poured into $20 \mathrm{~mL}$ of saturated sodium bicarbonate solution and extracted with ethyl acetate $(3 \times 25 \mathrm{~mL})$. The organic layers were combined, dried over magnesium sulfate, and concentrated in vacuo. The desired product was purified by silica gel column chromatography (3:1 hexanes-ethyl acetate) to give $39(0.281 \mathrm{~g}, 87 \%) .{ }^{1} \mathrm{H}-\mathrm{NMR}\left(300 \mathrm{MHz}, \mathrm{CDCl}_{3}\right) \delta 8.06-8.01(\mathrm{~m}, 2 \mathrm{H}), 7.57-7.51$ $(\mathrm{m}, 1 \mathrm{H}), 7.46-7.23(\mathrm{~m}, 7 \mathrm{H}), 5.14\left(\mathrm{ddt}, 1 \mathrm{H}, J_{4,3}=3.9 \mathrm{~Hz}, J_{4,5}=3.9 \mathrm{~Hz}, J_{4,5}=7.0 \mathrm{~Hz}, J_{4, \mathrm{~F}}=47.8\right.$ Hz, 4-H); 4.86 (d, $1 \mathrm{H}, J=11.6 \mathrm{~Hz}, \mathrm{CH}-H-\mathrm{Ph}), 4.72$ (d, $1 \mathrm{H}, J=11.6 \mathrm{~Hz}, \mathrm{CH}-H-\mathrm{Ph}), 4.58$ (ddd, $\left.1 \mathrm{H}, J_{5,4}=7.0 \mathrm{~Hz}, J_{5,5^{\prime}}=12.3 \mathrm{~Hz}, J_{5, \mathrm{~F}}=18.9 \mathrm{~Hz}, 5-\mathrm{H}\right), 4.50\left(\mathrm{ddd}, 1 \mathrm{H}, J_{5^{\prime}, 4}=3.9 \mathrm{~Hz}, J_{5,5^{\prime}}=12.3\right.$ 
$\left.\mathrm{Hz}, J_{5^{\prime}, \mathrm{F}}=27.3 \mathrm{~Hz}, 5^{\prime}-\mathrm{H}\right), 4.09-3.94\left(\mathrm{~m}, 2 \mathrm{H},-\mathrm{OCH}_{2^{-}}\right), 3.90-3.79\left(\mathrm{~m}, 2 \mathrm{H},-\mathrm{OCH}_{2^{-}}\right), 3.59(\mathrm{dd}, 1$ $\left.\mathrm{H}, J_{3,4}=3.9 \mathrm{~Hz}, J_{3, \mathrm{~F}}=22.5 \mathrm{~Hz}, 3-\mathrm{H}\right), 2.09-1.91(\mathrm{~m}, 1 \mathrm{H},-\mathrm{CH}-H-), 1.57\left(\mathrm{~d}, 3 \mathrm{H}, J_{1, \mathrm{~F}}=1.2 \mathrm{~Hz},-\right.$ $\left.\mathrm{CH}_{3}\right), 1.47-1.38(\mathrm{~m}, 1 \mathrm{H},-\mathrm{CH}-\mathrm{H}-) ;{ }^{13} \mathrm{C}-\mathrm{NMR}\left(75 \mathrm{MHz}, \mathrm{CDCl}_{3}\right) \delta 166.1,137.9,133.0,129.8$, 129.6, 128.4, 128.3, 127.7, $100.3(\mathrm{~d}, J=2.8 \mathrm{~Hz}), 90.9(\mathrm{~d}, J=177.0 \mathrm{~Hz}), 81.2(\mathrm{~d}, J=15.9 \mathrm{~Hz})$, 74.9, $64.5(\mathrm{~d}, J=24.2 \mathrm{~Hz}), 59.3(\mathrm{~d}, J=35.2 \mathrm{~Hz}), 25.4,15.0(\mathrm{~d}, J=4.4 \mathrm{~Hz}) ;{ }^{19} \mathrm{~F}-\mathrm{NMR}(282$ $\mathrm{MHz}, \mathrm{CDCl}_{3}$ ) $\delta-202.2$ (dddd, $J=18.9,22.5,27.3,47.8 \mathrm{~Hz}$ ). HRMS (CI) cald for $\mathrm{C}_{22} \mathrm{H}_{26} \mathrm{FO}_{5}$ 389.1764; found 389.1762.

2-(1,3-Dioxane)-3-O-benzyl-4-deoxy-4-fluoro-D-xylulose (40). Compound 39 (0.254 g, 0.65 mmol) was dissolved in $6 \mathrm{~mL}$ of HPLC grade methanol. To this stirred solution was added 2.8 M sodium methoxide/methanol ( $58 \mu \mathrm{L}, 0.25$ eq.). The mixture was kept at $-10^{\circ} \mathrm{C}$ for $9 \mathrm{~h}$ then neutralized by successive addition of concentrated sulfuric acid and triethylamine. The reaction mixture was concentrated in vacuo and purified by silica gel column chromatography to yield $\mathbf{3 9}$ as a syrup $(0.180 \mathrm{~g}, 97 \%) .{ }^{1} \mathrm{H}-\mathrm{NMR}\left(300 \mathrm{MHz}, \mathrm{CDCl}_{3}\right) \delta$ 7.40-7.20 (m, $\left.5 \mathrm{H}, \mathrm{PhHs}\right), 4.80$ (ddt, 1 $\left.\mathrm{H}, J_{4,3}=5.3 \mathrm{~Hz}, J_{4,5}=5.0 \mathrm{~Hz}, J_{4, \mathrm{~F}}=47.2 \mathrm{~Hz}, 4-\mathrm{H}\right) ; 4.75\left(\mathrm{t}, 2 \mathrm{H}, J=10.6 \mathrm{~Hz},-\mathrm{CH}_{2}-\mathrm{Ph}\right), 4.13-$ $3.68\left(\mathrm{~m}, 6 \mathrm{H}, \mathrm{H}-5, \mathrm{H}-5^{\prime}, 2 \times-\mathrm{OCH}_{2^{-}}\right), 3.60\left(\mathrm{dd}, 1 \mathrm{H}, J_{3,4}=5.3 \mathrm{~Hz}, J_{3, \mathrm{~F}}=19.5 \mathrm{~Hz}, 3-\mathrm{H}\right), 2.52(\mathrm{dd}$, $1 \mathrm{H}, J=4.5 \mathrm{~Hz}, J=9.3 \mathrm{~Hz},-\mathrm{OH}), 2.09-1.85(\mathrm{~m}, 1 \mathrm{H},-\mathrm{CH}-H-), 1.54\left(\mathrm{~d}, 3 \mathrm{H}, J_{1, \mathrm{~F}}=1.1 \mathrm{~Hz},-\right.$ $\left.\mathrm{OCH}_{3}\right), 1.50-1.38(\mathrm{~m}, 1 \mathrm{H},-\mathrm{CH}-\mathrm{H}-) ;{ }^{13} \mathrm{C}-\mathrm{NMR}\left(75 \mathrm{MHz}, \mathrm{CDCl}_{3}\right) \delta 138.0,128.3,128.2,127.7$, $100.4(\mathrm{~d}, J=5.9 \mathrm{~Hz}), 93.9(\mathrm{~d}, J=173.0 \mathrm{~Hz}), 81.6(\mathrm{~d}, J=17.4 \mathrm{~Hz}), 75.2,63.0(\mathrm{~d}, J=22.7 \mathrm{~Hz})$, $59.4(\mathrm{~d}, J=8.1 \mathrm{~Hz}), 25.2,15.0(\mathrm{~d}, J=4.4 \mathrm{~Hz}) ;{ }^{19} \mathrm{~F}-\mathrm{NMR}\left(282 \mathrm{MHz}, \mathrm{CDCl}_{3}\right) \delta-199.5(\mathrm{dddd}, J=$ 19.5, 21.9, 28.8, 47.2 Hz). HRMS (CI) cald for $\mathrm{C}_{15} \mathrm{H}_{22} \mathrm{FO}_{4}$ 285.1502; found 285.1502.

Dimethyl 2-(1,3-Dioxane)-3-O-benzyl-4-deoxy-4-fluoro-D-xylulose-5-phosphate (41). To a solution of compound $40(0.167 \mathrm{~g}, 0.587 \mathrm{mmol})$ in $6 \mathrm{~mL}$ anhydrous methylene chloride was added 2,6-lutidine ( $0.14 \mathrm{~mL}, 2.1$ eq. $)$ and trimethyl phosphine $(0.12 \mathrm{~mL}, 1.8$ eq.) and cooled to 4 
${ }^{\circ} \mathrm{C}$. To this was added tellurium tetrachloride $(0.128 \mathrm{~g}, 0.8 \mathrm{eq}$. $)$. The mixture was stirred at room temperature for $1 \mathrm{~h}$, then concentrated in vacuo and purified by silica gel chromatography (1:1 ethyl acetate-hexanes) to afford $\mathbf{4 1}(0.208 \mathrm{~g})$ in $90 \%$ yield. ${ }^{1} \mathrm{H}-\mathrm{NMR}\left(300 \mathrm{MHz}, \mathrm{CDCl}_{3}\right) \delta 7.36-$ $7.20(\mathrm{~m}, 5 \mathrm{H}, \mathrm{PhHs}), 4.97\left(\mathrm{ddt}, 1 \mathrm{H}, J_{4,3}=4.2 \mathrm{~Hz}, J_{4,5}=6.5, J_{4, \mathrm{~F}}=48.0 \mathrm{~Hz}, 4-\mathrm{H}\right) ; 4.78(\mathrm{~d}, 1 \mathrm{H}, J$ $=11.1 \mathrm{~Hz}, \mathrm{CH}-H-\mathrm{Ph}), 4.64(\mathrm{~d}, 1 \mathrm{H}, J=11.1 \mathrm{~Hz}, \mathrm{CH}-H-\mathrm{Ph}), 4.33-4.10\left(\mathrm{~m}, 2 \mathrm{H}, 5-\mathrm{H}_{2}\right), 4.06-3.91$ $\left(\mathrm{m}, 2 \mathrm{H},-\mathrm{OCH}_{2}-\right), 3.87-3.77\left(\mathrm{~m}, 2 \mathrm{H},-\mathrm{OCH}_{2}-\right), 3.75(\mathrm{~d}, 3 \mathrm{H}, J=1.2 \mathrm{~Hz}, \mathrm{OMe}), 3.71(\mathrm{~d}, 3 \mathrm{H}, J=$ $1.2 \mathrm{~Hz}, \mathrm{OMe}), 3.48\left(\mathrm{dd}, 2 \mathrm{H}, J_{3,4}=4.2 \mathrm{~Hz}, J_{3, \mathrm{~F}}=21.9 \mathrm{~Hz}, 3-\mathrm{H}\right), 2.03-1.82(\mathrm{~m}, 1 \mathrm{H},-\mathrm{CH}-H-)$, $1.50\left(\mathrm{~d}, 3 \mathrm{H}, J_{1, \mathrm{~F}}=1.2 \mathrm{~Hz},-\mathrm{CH}_{3}\right), 1.46-1.38(\mathrm{~m}, 1 \mathrm{H},-\mathrm{CH}-\mathrm{H}-) ;{ }^{13} \mathrm{C}-\mathrm{NMR}\left(75 \mathrm{MHz}, \mathrm{CDCl}_{3}\right)$ $\delta 137.8,128.3,127.7,100.1(\mathrm{~d}, J=2.7), 90.8(\mathrm{dd}, J=7.7,178.7), 80.8(\mathrm{~d}, J=16.5), 74.9(\mathrm{~d}, J=$ 1.7), $67.2(\mathrm{dd}, J=5.5,32.3), 59.3(\mathrm{~d}, J=35.8), 54.3(\mathrm{dd}, J=3.8,6.0), 25.4,15.1(\mathrm{~d}, J=4.4)$; ${ }^{19} \mathrm{~F}-\mathrm{NMR}\left(282 \mathrm{MHz}, \mathrm{CDCl}_{3}\right) \delta-202.7(\mathrm{ddt}, J=21.9,26.4,48.0 \mathrm{~Hz}) ;{ }^{31} \mathrm{P}-\mathrm{NMR}(121 \mathrm{MHz}$, $\left.\mathrm{CDCl}_{3}\right) \delta$ 2.24. HRMS (CI) cald for $\mathrm{C}_{17} \mathrm{H}_{27} \mathrm{FO}_{7} \mathrm{P}$ 393.1478; found 393.1484.

4-Deoxy-4-fluoro-D-xylulose-5-phosphate (7). To a solution of compound 41 (34.3 mg, $0.087 \mathrm{mmol})$ in $650 \mu \mathrm{L}$ of deuterated chloroform was added trimethylsilyl bromide $(0.026 \mathrm{~mL}$, 2.15 eq.) and the mixture stirred for $1 \mathrm{~h}$ at room temperature. Upon completion of the reaction (as monitored by ${ }^{1} \mathrm{H}$-NMR), the mixture was concentrated in vacuo and redissolved in $0.3 \mathrm{~mL}$ of water/0.6 mL methanol. The hydrogenation catalyst, $10 \%$ palladium on carbon (10 mg, $1.1 \mathrm{eq}$.$) ,$ was added and the suspension was stirred for $16 \mathrm{~h}$ under hydrogen gas, then filtered through Celite 545 and concentrated in vacuo. The crude mixture was diluted with $1 \mathrm{~mL}$ of water, neutralized with sodium bicarbonate, and lyophilized. The resulting foam was dissolved in a minimum amount of water and methanol and purified by cellulose chromatography (Whatman CF-11) (9:1 tetrahydrofuran-0.1\% trifluoroacetic acid). The desired fractions were pooled and concentrated by lyophilization $(7.3 \mathrm{mg}, 43 \%) .{ }^{1} \mathrm{H}-\mathrm{NMR}\left(500 \mathrm{MHz}, \mathrm{D}_{2} \mathrm{O}\right) \delta 5.18$ (dddd, $1 \mathrm{H}, J_{4,3}$ $\left.=2.0 \mathrm{~Hz}, J_{4,5}=5.0 \mathrm{~Hz}, J_{4,5}=7.0 \mathrm{~Hz}, J_{4, \mathrm{~F}}=46.9 \mathrm{~Hz}, 4-\mathrm{H}\right), 4.47\left(\mathrm{dd}, J_{3,4}=2.0 \mathrm{~Hz}, J_{3, \mathrm{~F}}=32.4 \mathrm{~Hz}\right.$, 
3-H), 4.12-3.93 (m, $\left.2 \mathrm{H}, 5-\mathrm{H}_{2}\right), 2.26\left(\mathrm{~s}, 3 \mathrm{H},-\mathrm{CH}_{3}\right) ;{ }^{13} \mathrm{C}-\mathrm{NMR}\left(126 \mathrm{MHz}, \mathrm{D}_{2} \mathrm{O}\right) \delta 211.3(\mathrm{~d}, J=$ $2.8 \mathrm{~Hz}), 91.9(\mathrm{dd}, J=7.6,175.6 \mathrm{~Hz}), 75.9(\mathrm{~d}, J=20.4 \mathrm{~Hz}), 64.0(\mathrm{dd}, J=5.1,25.5 \mathrm{~Hz}), 26.2 ;{ }^{19} \mathrm{~F}-$ NMR (282 MHz, $\left.\mathrm{D}_{2} \mathrm{O}\right) \delta-204.5--205.0(\mathrm{~m}) ;{ }^{31} \mathrm{P}-\mathrm{NMR}\left(121 \mathrm{MHz}, \mathrm{D}_{2} \mathrm{O}\right) \delta$ 1.3. HRMS (CI) cald for $\mathrm{C}_{5} \mathrm{H}_{11} \mathrm{FO}_{6} \mathrm{P} 215.0121$; found 215.0111 . 